\title{
Effect of powder metallurgy synthesis parameters for pure aluminium on resultant mechanical properties
}

\author{
Jinghang Liu ${ }^{1,2}$, Javier Silveira ${ }^{1,2}$, Robert Groarke ${ }^{1,2, *}$, Sohan Parab ${ }^{1,2}$, Harshaan Singh ${ }^{1,2}$, Eanna \\ McCarthy ${ }^{1,2}$, Shadi Karazi ${ }^{1,2}$, Andre Mussatto ${ }^{2}$, Jared Houghtaling ${ }^{1,2}$, Inam Ul Ahad ${ }^{1,2}$, Sumsun \\ Naher $^{1,3}$, Dermot Brabazon ${ }^{1,2}$ \\ ${ }^{1}$ Advanced Processing Technology Research Centre, Dublin City University, Dublin 9, Ireland \\ ${ }^{2}$ School of Mechanical \& Manufacturing Engineering, Dublin City University, Dublin 9, Ireland \\ ${ }^{3}$ Department of Mechanical Engineering and Aeronautics, City University London, UK \\ *E-mail: robert.groarke@dcu.ie
}

\begin{abstract}
In this work, pure aluminium powders of different average particle size were compacted, sintered into discs and tested for mechanical strength at different strain rates. The effects of average particle size $(15,19$, and $35 \mu \mathrm{m})$, sintering rate $\left(5\right.$ and $\left.20^{\circ} \mathrm{C} / \mathrm{min}\right)$ and sample indentation test speed $(0.5,0.7$, and $1.0 \mathrm{~mm} / \mathrm{min})$ were examined. A compaction pressure of $332 \mathrm{MPa}$ with a holding time of six minutes was used to produce the green compacted discs. The consolidated green specimens were sintered with a holding time of 4 hours, a temperature of $600{ }^{\circ} \mathrm{C}$ in an argon atmosphere. The resulting sintered samples contained higher than $85 \%$ density. The mechanical properties and microstructure were characterized using indentation strength measurement tests and SEM analysis respectively. After sintering, the aluminium grain structure was observed to be of uniform size within the fractured samples. The indentation test measurements showed that for the same sintering rate, the $35 \mu \mathrm{m}$ powder particle size provided the highest radial and tangential strength while the $15 \mu \mathrm{m}$ powder provided the lowest strengths. Another important finding from this work was the increase in sintered sample strength which was achieved using the lower sinter heating rate, $5^{\circ} \mathrm{C} / \mathrm{min}$. This resulted in a tangential stress value of $365 \mathrm{MPa}$ which was significantly higher than achieved, $244 \mathrm{MPa}$, using the faster sintering heating rate, $20^{\circ} \mathrm{C} / \mathrm{min}$.
\end{abstract}

Keywords: aluminium, powder metallurgy (P/M), indentation, sintering, green compaction. 


\section{Introduction}

Pure aluminium has many important applications in consumer products, electrical and electronic engineering, and structural engineering [1]-[4]. In consumer products, aluminium is most noted in packaging applications. Due to its effect as an impermeable barrier and its non-toxicity, pure aluminium is widely used in packaging applications [5], [6]. Aluminium is one of the lightest engineering metals, having a strength to weight ratio superior to steel, however alloying with other elements is necessary to provide the higher strengths needed for structural applications. In this study, aluminium alloys with less than $1 \%$ alloying elements are considered as pure aluminium. Aluminium alloys based around pure aluminium predominantly, are used in automotive, aerospace, and shipbuilding industries [7]-[9]. Due to its unique visco-elastic mechanical response, nearly pure aluminium alloy EN-AW 1050A H24 has recently been proposed as structural shock load absorbing elements in building construction in areas of seismic activity [3]. The chemical composition of Al 1050A H24 has commercial denomination of Al $99.50 \%$ with alloying elements $0.07 \% \mathrm{Zn}, 0.02 \% \mathrm{Ti}, 0.02 \%$ others and has $0.02 \% \mathrm{Cu}, 0.40 \% \mathrm{Fe}$, and $0.31 \% \mathrm{Si}$ impurities [3].

In electrical engineering, pure aluminium is used instead of copper in power line applications due to it being more than three times less dense. While aluminium delivers $65 \%$ the conductivity of copper, it provides double the conductivity for the same weight of material. The strongly protective aluminium oxide layer also results in lower maintenance costs compared to other metallic alternatives. Due to its ductility, aluminium can be more easily drawn into long thin wires and the high recyclable nature of aluminium also promotes it use in many applications [10]-[12]. Electrical components such as capacitors, rectifiers, as well as semiconductor compounds, e.g. AIIIBV, microprocessors, cryoelectronics, and satellite dishes are also produced with pure aluminium [12]-[14]. Other applications of pure aluminium include mirror reflectors and as a structural material in nuclear reactors [15], [16].

Here in this contribution, we present a study on the mechanical strength of pure aluminium compacts produced using cold compaction followed by inert atmosphere furnace sintering. The powder metallurgy route of cold compaction followed by furnace sintering was recently used to provide densities of sintered specimens at $88 \%$ [17]. A number of studies have been performed to reduce the high number of steps required by HIP, hot extrusion, vacuum hot pressing and hot-rolling [18-22], nevertheless the cold $\mathrm{P} / \mathrm{M}$ route is preferential for providing pure and exact materials compositions, without the need for a high-cost facility. The $\mathrm{P} / \mathrm{M}$ route can produce near net shape components with fine and uniform microstructure [23]. It can also provide better thermal stability as well as increased corrosion and tribological properties compared to alternative production techniques [24]. However, a number of complexities need to be overcome during the process of direct pure aluminium powder compaction and sintering. These complexities arise mainly because of the existence of a firm and intense oxide layer covering the powder particles. This oxide layer leads to a reduction in both compressibility, thermal conductivity and ultimately in the ability to sinter these powders [25].

For a specific $\mathrm{P} / \mathrm{M}$ processing method, the strength of pure aluminium compacts must be established as a base point of comparison before final applications and including applications requiring reinforcement are 
examined. This would provide a better fundamental understanding of how these additions can contribute to the overall material properties and final applications of these $\mathrm{P} / \mathrm{M}$ parts as light, corrosion resistant, or strong high temperature materials. As such the main objective of this study was to synthesis pure aluminium disk specimens with powder metallurgy and correlate the process parameters with the resulting mechanical properties.

\section{Experimental procedure}

\subsection{Materials}

Aluminium powders with an average particle size of $15 \mu \mathrm{m}, 19 \mu \mathrm{m}$ and $35 \mu \mathrm{m}$ were purchased from commercial sources (Goodfellow Ltd. and East Coast Supplies Ltd.) as shown in Figure 1 and detailed in Table 1. Confirmatory particle size measurements were performed using a Malvern Mastersizer S. With the as-received pure powder, disk shaped specimens were made using cold compaction and consolidation sintering. $\mathrm{D}_{90}$ values for this powder were found to be $<60 \mu \mathrm{m}$. All experimental measurements were recorded three times, $\mathrm{n}=3$. Average results values and $95 \%$ confidence intervals were calculated and presented.

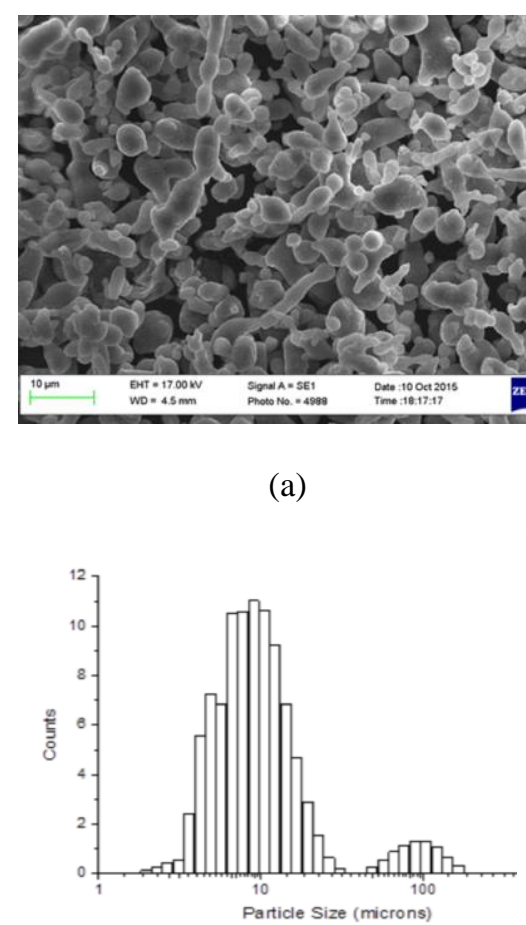

(d)

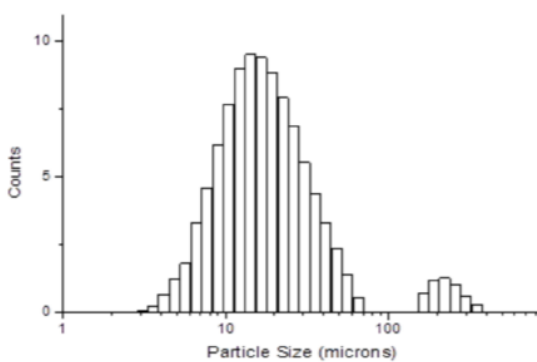

(e)

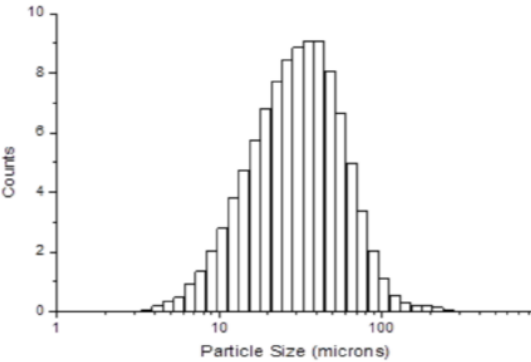

(f)

Fig. 1 Scanning electron micrographs of aluminium particles of (a) Goodfellow aluminium powder with mean particle size of $15 \mu \mathrm{m}$, (b) Goodfellow aluminium powder with mean particle size of $19 \mu \mathrm{m}$, (c) East Coast Fibreglass aluminium powder with mean particle size of $35 \mu \mathrm{m}$ and with mixed morphology; size distributoins of (d) the $15 \mu \mathrm{m}$ mean powder particle size, (e) the $19 \mu \mathrm{m}$ mean powder particle size, and (f) the $35 \mu \mathrm{m}$ mean powder particle size. 
Table 1. Measured particle size and specifications of the aluminium powders investigated.

\begin{tabular}{|c|c|c|c|}
\hline Material & Source & Particle Size $(\boldsymbol{\mu m})$ & Purity \\
\hline Powder \#1 & \multirow{2}{*}{ Goodfellow Cambridge Ltd. } & $15 \pm 3.3$ & \multirow{2}{*}{$99.00 \%$} \\
\cline { 1 - 2 } & & $19 \pm 5.9$ & \\
\hline Powder \#2 & & $35 \pm 1$ & $99.50 \%$ \\
\hline
\end{tabular}

69

\subsection{Aluminium powder metallurgy}

During placement of the powder into the die for cold compaction, the powder particles were gently vibrated to provide better packing and thereby decreased porosity. The pressure was gradually increased to the set level. During compaction the individual particles are deformed and cold welded which gives rise to the green compact strength [24]. The value of green density generally increases with increased compaction pressure and better packing. It has been reported previously that full density could be achieved with aluminium alloy powders at a sufficiently high compaction pressure [26]. Unalloyed atomised aluminium powders $(<20 \mu \mathrm{m})$ have also been reported to be consolidated to $100 \%$ density with a pressure of $1 \mathrm{GPa}$ [23]. Higher green density after compaction enables the sintering process to proceed more efficiently. For the aluminium samples, a uniaxial hydraulic press (George E Moore and Son, Birmingham, UK) was used to produce the green compacts. The cylindrical die and resulting thin cylindrical shapes were formed as shown in Fig. 2. For each compaction, $1.5 \mathrm{~g}$ of powder was compacted which resulted in a $1.5 \mathrm{~mm}$ thick samples with a diameter of $26 \mathrm{~mm}$. All of the samples were produced at room temperatures between 18 and $25{ }^{\circ} \mathrm{C}$. The compaction force applied for six minutes was $176 \mathrm{kN}$ corresponding to a pressure of $332 \mathrm{MPa}$. This pressure limit was chosen in order to avoid damage to the die and sample during extraction. From a study of collaborating industry partner facilities, it was found that this pressure level would also be possible to implement within their facilities. Compaction and forming processes have been developed to deliver much higher pressures such as in the work of Wideroe et al [22] and in the ECAP process [27], however most commercial and research forming machines work at much lower pressure levels [28]. Rhombic boron nitride powder as lubricant was physically dusted onto the mould wall to avoid the edge cracking of the green compacts during the demoulding process. 


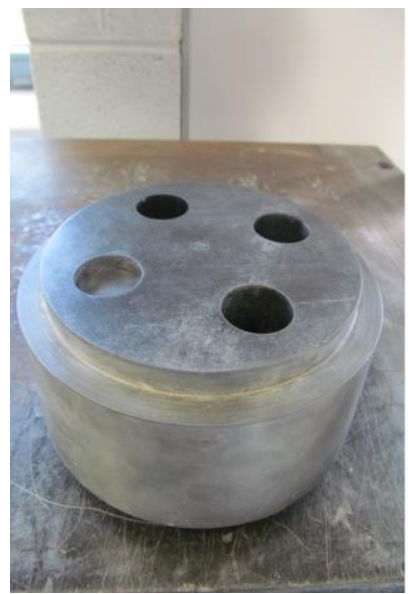

(a)

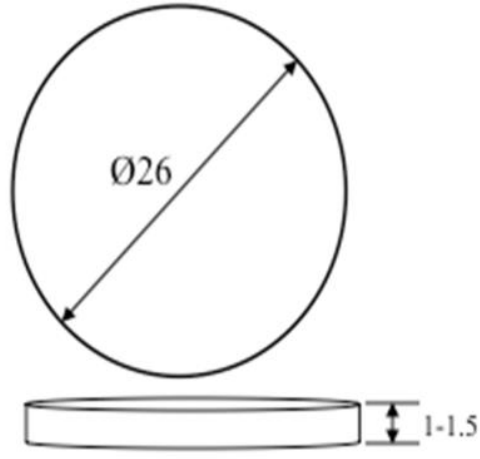

(b)

Fig. 2 (a) Picture of compaction mould and (b) schematic of produced specimen dimensions (mm).

The theoretical solid density of pure aluminium is $2.7 \mathrm{~g} / \mathrm{cm}^{3}$ while that of the loose powder used in this research is about $1.43 \mathrm{~g} / \mathrm{ml}$ (approx. $70 \mathrm{ml}$ for every $100 \mathrm{~g}$ of aluminium powder). The density of the green samples was measured by Archimedes method. For a higher applied pressure, a higher green density would be expected to result. For the pressures used in this study, the sintered densities obtained at the maximum pressure of $332 \mathrm{MPa}$ were measured as $85.2 \%$. Pure aluminium can be sintered in nitrogen, dissociated ammonia, argon, or vacuum [29]. For the DTA, a $20{ }^{\circ} \mathrm{C} / \mathrm{min}$ ramp rate in argon atmosphere was applied to the maximum temperature of $900{ }^{\circ} \mathrm{C}$ while the measurements were taken at one second intervals. The as-received aluminium powder of $15 \mu \mathrm{m}, 19 \mu \mathrm{m}$ and $35 \mu \mathrm{m}$ particles sizes melted at temperature of $675+/-4{ }^{\circ} \mathrm{C}$. The oxidation and liquidus temperatures of the powders used were firstly determined using differential thermal analysis (DTA), Stanton Redcroft

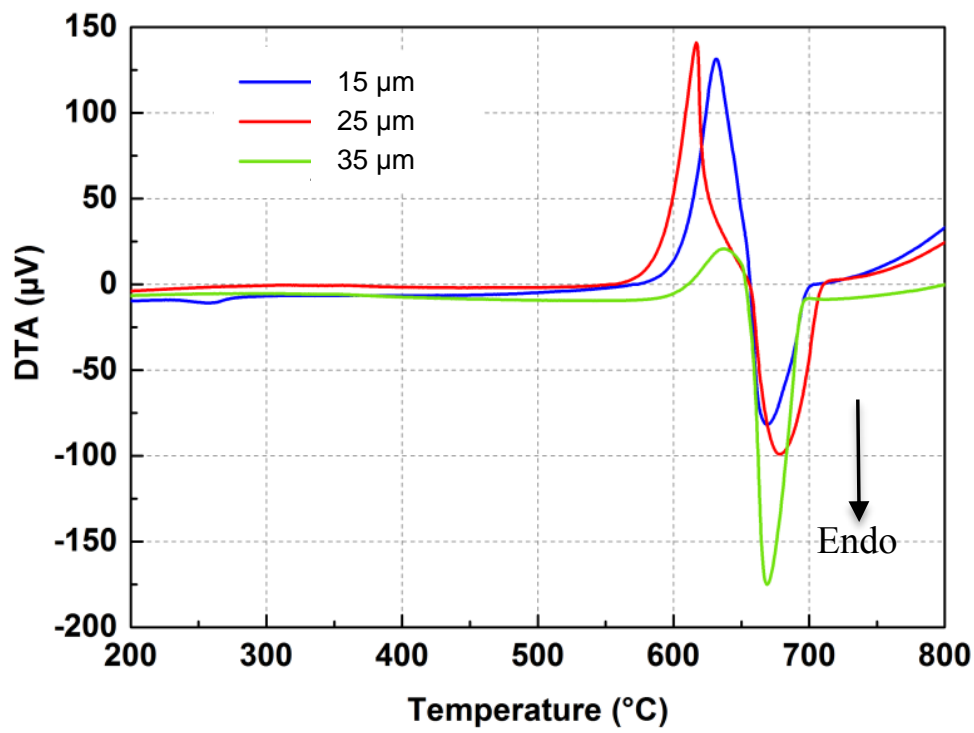

Fig. 3 Differential readings against the temperature of the aluminium powders. 
The nominal melting point for pure aluminium is $660.3{ }^{\circ} \mathrm{C}$ but this value is influenced by many factors, sintering temperature was $600^{\circ} \mathrm{C}$ (slightly less than $90 \%$ of the melting temperature), which meets the "rule of thumb" that the sintering temperature is usually set between $70 \%$ and $90 \%$ of the melting point of the metal. It is well known that insufficient sintering time, overly fast heating rate or short sintering holding time can cause insufficient diffusion within the sintered aluminium specimens [25]. To accomplish sintering of the compacted samples presented in this work, a horizontal tube furnace, Carbolite model 3216 with Eurotherm temperature controller was used. Green samples were positioned in center of the furnace and the temperature of furnace was ramped up from room temperature at a rate of $20{ }^{\circ} \mathrm{C} / \mathrm{min}$ (or $5{ }^{\circ} \mathrm{C} / \mathrm{min}$ for comparison purpose) until the maximum temperature, $600^{\circ} \mathrm{C}(88 \%$ of the melting temperature) was reached. The maximum temperature was held for 4 hours, and the furnace was then naturally cooled to room temperature. In this study, an argon inert atmosphere was used during sintering which resulted in well-sintered samples. After sintering, disk samples as shown in Fig. 4 were produced.

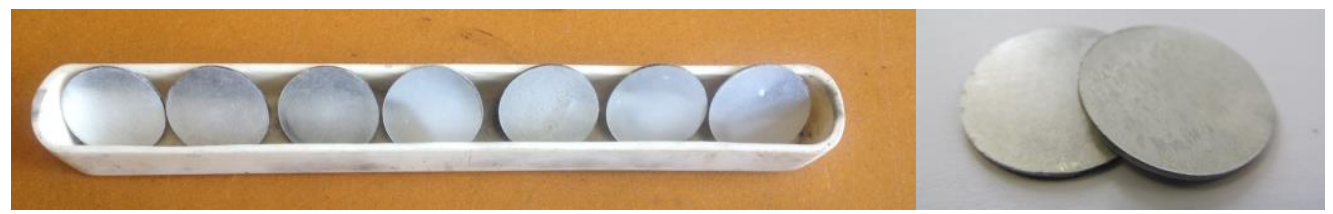

(a)

(b)

Fig. 4 (a) Picture of ceramic tundish with pure aluminium disk samples after compaction and sintering: $1.5 \mathrm{~g}$ aluminium powder with argon at a flow rate $1.5 \mathrm{~mL} / \mathrm{min}$, temperature of $600{ }^{\circ} \mathrm{C}$, and a holding time 4 hours; and (b) enlarged picture of disk samples in (a).

\section{Specimen characterization}

\subsection{Indentation testing of disk samples}

After the sintered disk samples of the different particle sizes were fabricated, they were indentation tested with a five millimeter protrusion indenter on a Zwick Roell, UK, universal testing machine (Z005, T1FR005TN.A50), as shown in Fig. 5(a). Figure 5 (b) shows some of the samples post testing. Three loading velocities were examined during these tests, $0.5,0.7$ and $1 \mathrm{~mm} / \mathrm{min}$. 


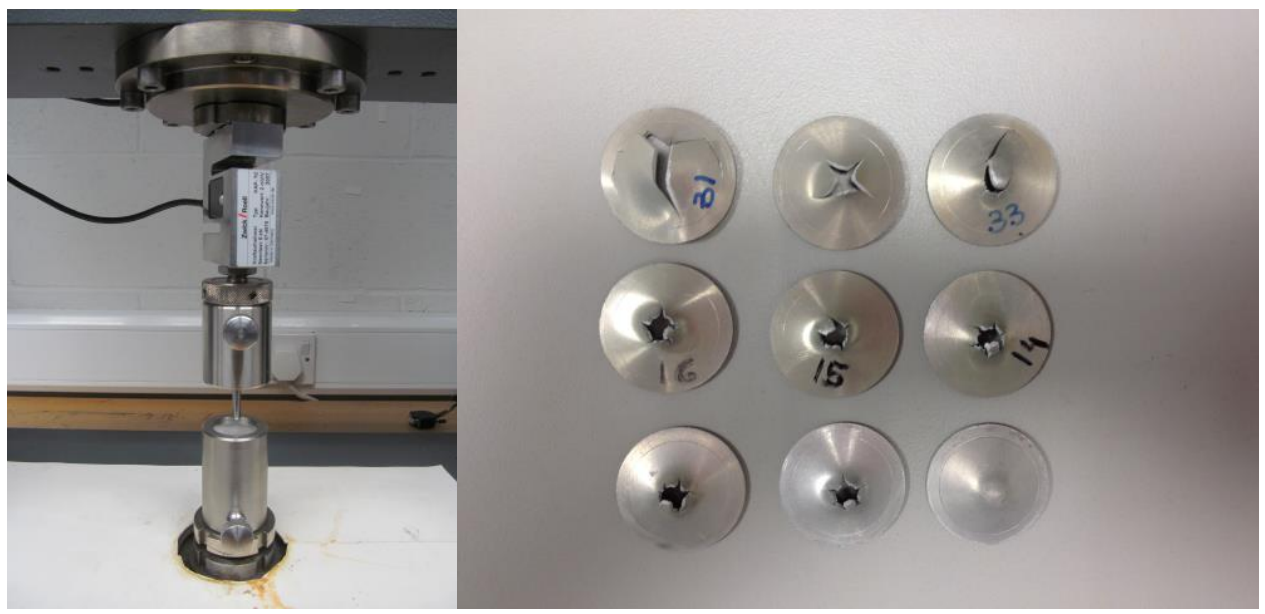

(a) (b)

Fig. 5 (a) Picture of indentation test configuration, and (b) disk samples after indentation testing; from top to bottom row, specimens are of $15 \mu \mathrm{m}, 19 \mu \mathrm{m}$, and $35 \mu \mathrm{m}$ powder; while from left to right column, test speeds represented are $0.5,0.7$ and $1 \mathrm{~mm} / \mathrm{min}$.

Based on the force recorded by the load cell, the sample deflection of the disk can be calculated from the process parameters using equation 1 [30],

$$
y=\frac{3 P R^{2}}{4 \pi E t^{3}}(3+v)(1-v)
$$

where $y$ is the deflection in the sample centre, $P$ is the vertical load in central point, $R$ is the radius of the circular solid disk, $t$ represents the thickness of disk, $E$ is Young's modulus of the aluminium (70 GPa), and $v$ equals to the Poisson's ratio of aluminium (0.35). The radial stress $\sigma_{r}$ and tangential stress $\sigma_{t}$ can be calculated via Equation 2 and 3 as follows,

$$
\begin{gathered}
\sigma_{r}=\frac{3 P}{2 \pi t^{2}}(1+v) \log \frac{R}{x}=0.31 P \\
\sigma_{r}=\frac{3 P}{2 \pi t^{2}}\left[(1+v) \log \frac{R}{x}+(1-v)\right]=0.51 P
\end{gathered}
$$

where $x$ represents the diameter of the indenter. The axial stress $\sigma_{a}$ was neglected in comparison to the radial and tangential stress [30, 31]. Based on these equations stress values were calculated and plotted against displacement, see Fig. 6. Recorded fracture displacements and corresponding radial and tangential stress values are listed in Table 2. Aluminium particle size and sintering rate both had influence on the displacement at which fracture occurred as well as on the corresponding radial and tangential stress. For example, with 0.5 $\mathrm{mm} / \mathrm{min}$ testing speed, the $35 \mu \mathrm{m}$ powder particle size provided the largest displacement before failure while the $15 \mu \mathrm{m}$ average particle samples gave the smallest displacement. It was also observed that a significantly higher radial and tangential stress were achieved (221 MPa and $365 \mathrm{MPa}$ respectively) for the samples with $35 \mu \mathrm{m}$ 
mean particle size which were prepared with a sintering rate of $5{ }^{\circ} \mathrm{C} / \mathrm{min}$ and tested with an indentation rate of $0.5 \mathrm{~mm} / \mathrm{min}$, in comparison to the smaller staring particle sizes. The fracture displacements of the samples are shown in

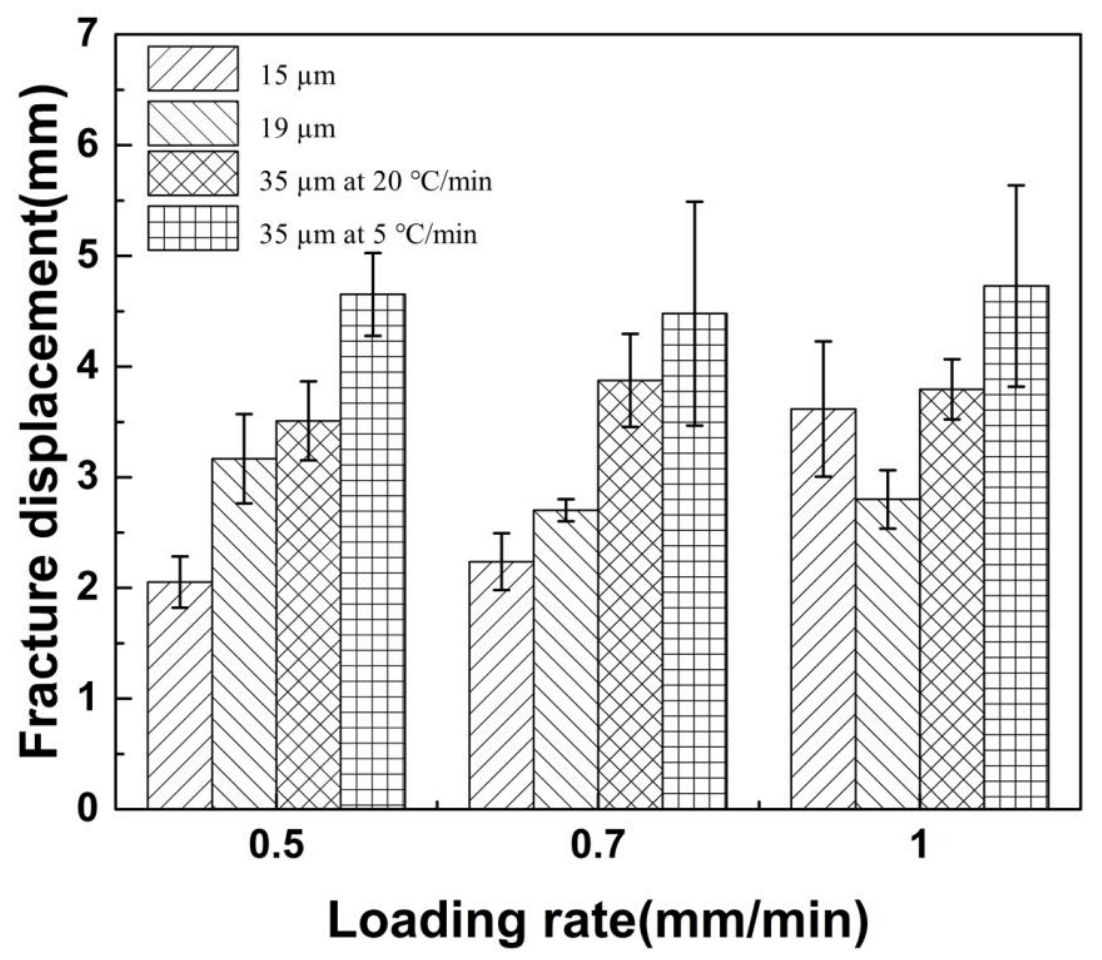

Fig. 7 and the radial and tangential stresses are shown in Fig. 8. The $35 \mu \mathrm{m}$ mean particle size produced samples with sintering rate of $5{ }^{\circ} \mathrm{C} / \mathrm{min}$ provided the highest strength samples under all testing velocities. The $35 \mu \mathrm{m}$ powder which contained a mixed morphology and wider size distribution, had significantly improved ductility due to reduced porosity, as observed from SEM images, in the compacted and sintered sample structure. The lower sintering rate repeatedly resulted in increased sample strength relative to the higher sintering rate of 20 ${ }^{\circ} \mathrm{C} / \mathrm{min}$. 


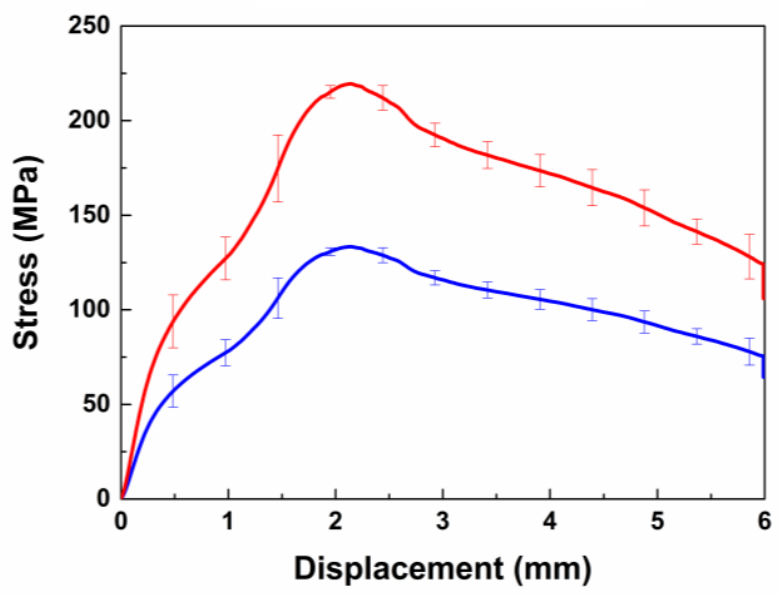

(a)

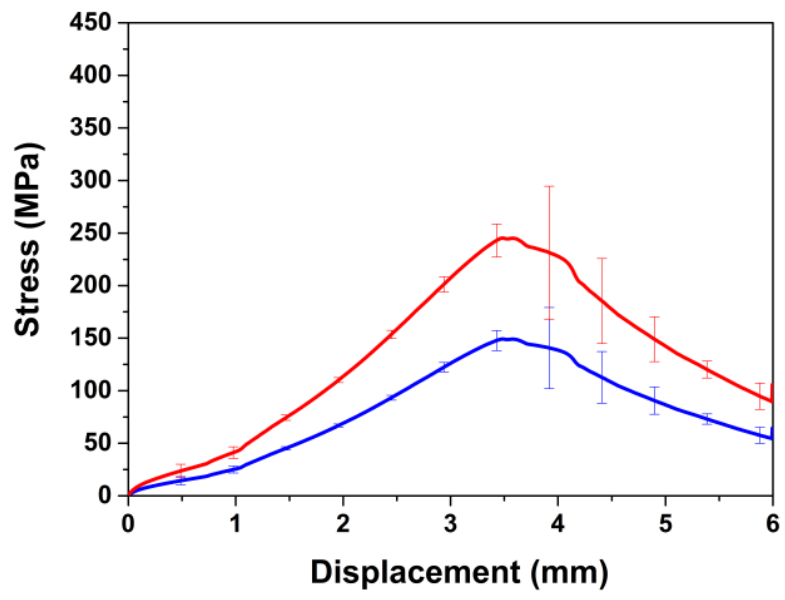

(c)

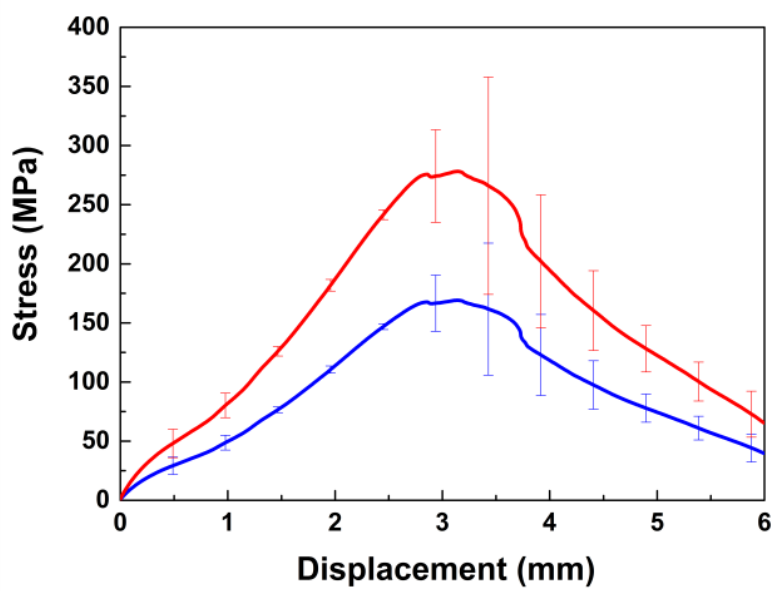

(b)

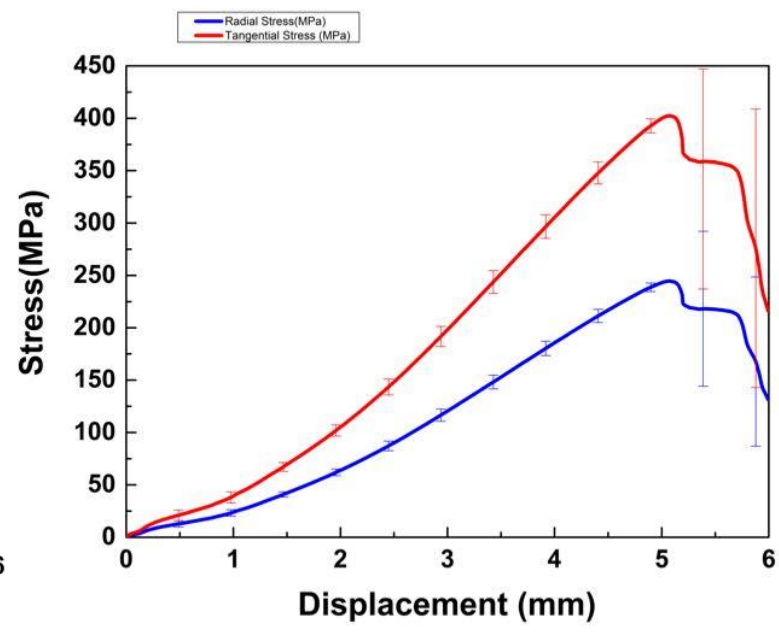

(d)

Fig. 6 Stress versus displacement of pure aluminium samples of particle size (a) $15 \mu \mathrm{m}$, (b) $19 \mu \mathrm{m}$, (c) 35 $\mu \mathrm{m}$ sintered at $20{ }^{\circ} \mathrm{C} / \mathrm{min}$, and (d) $35 \mu \mathrm{m}$ sintered at $5{ }^{\circ} \mathrm{C} / \mathrm{min}$. Radial stress and tangential stress are represented by blue and red lines respectively, $\mathrm{n}=3$.

Table 2. Recorded averaged fracture displacement, $y$, radial stress, $\sigma_{r}$, and tangential stress, $\sigma_{t}$, under the testing speeds of $0.5,0.7$ and $1 \mathrm{~mm} / \mathrm{min}, \mathrm{n}=3$.

\begin{tabular}{c|c|c|c|c}
\hline \multicolumn{2}{c|}{ Testing speed of } & $0.5 \mathrm{~mm} / \mathrm{min}$ & $0.7 \mathrm{~mm} / \mathrm{min}$ & $1 \mathrm{~mm} / \mathrm{min}$ \\
\hline $\begin{array}{c}\text { Particle size } \\
(\mu \mathrm{m})\end{array}$ & $\begin{array}{c}\text { Sintering rate } \\
\left({ }^{\circ} \mathrm{C} / \mathrm{min}\right)\end{array}$ & \multicolumn{3}{|c}{$\begin{array}{c}{\left[y, \sigma_{r}, \sigma_{t]}\right]} \\
(\mathrm{mm}, \mathrm{MPa}, \mathrm{MPa})\end{array}$} \\
\hline 15 & 20 & $2.1,135,222$ & $2.2,138,227$ & $3.6,84,138$ \\
\hline 19 & 20 & $3.1,186,306$ & $2.7,149,245$ & $2.8,177,1292$ \\
\hline 35 & 20 & $3.5,148,244$ & $3.8,171,282$ & $3.7,157,258$ \\
\hline 35 & 5 & $\mathbf{4 . 6 , 2 2 2 , 3 6 5}$ & $4.4,199,328$ & $4.7,219,1380$ \\
\hline
\end{tabular}




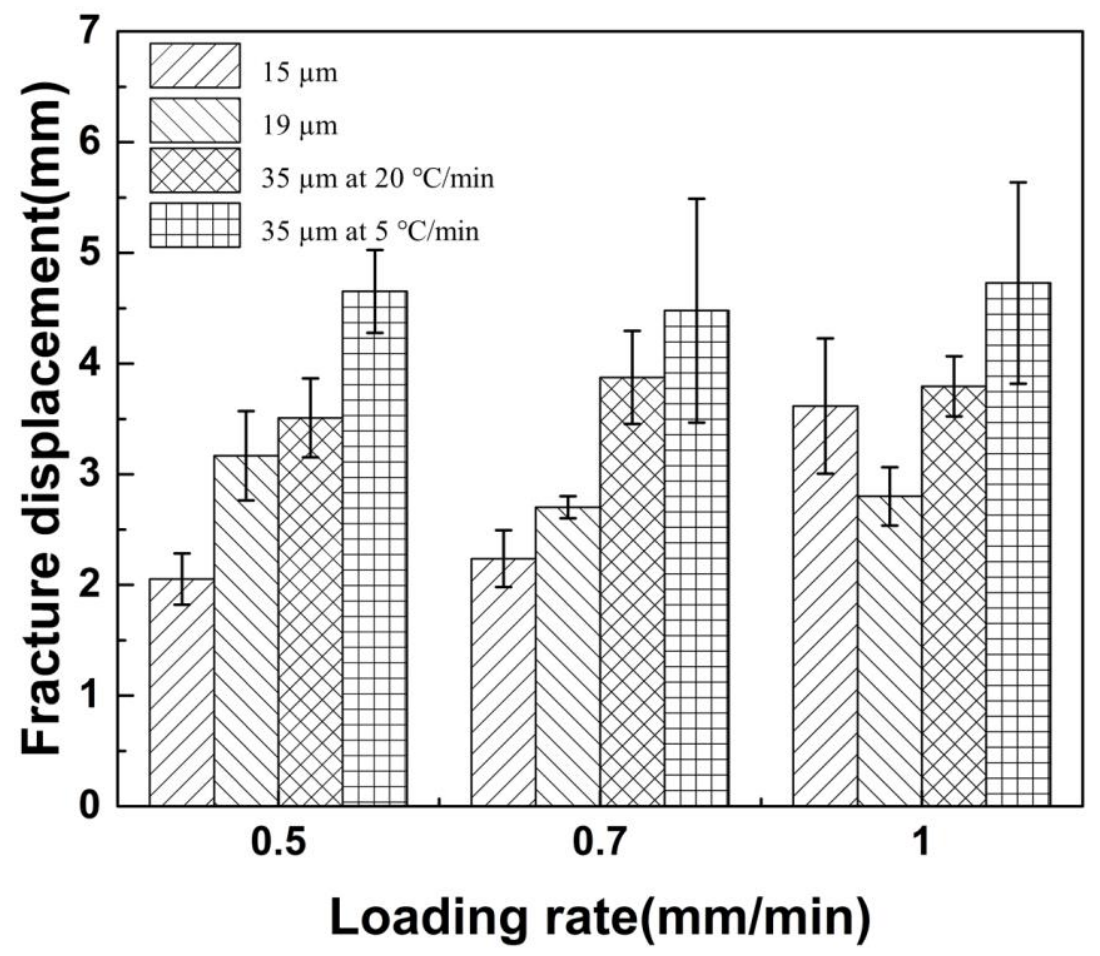

Fig. 7 Fracture displacement under the testing speed of $0.5,0.7$, and $1 \mathrm{~mm} / \mathrm{min}$. Default sintering rate for $19115 \mu \mathrm{m}, 19 \mu \mathrm{m}$ and $35 \mu \mathrm{m}$ powder was $20^{\circ} \mathrm{C} / \mathrm{min} ; \mathrm{n}=3 ; 95 \%$ confidence intervals shown.

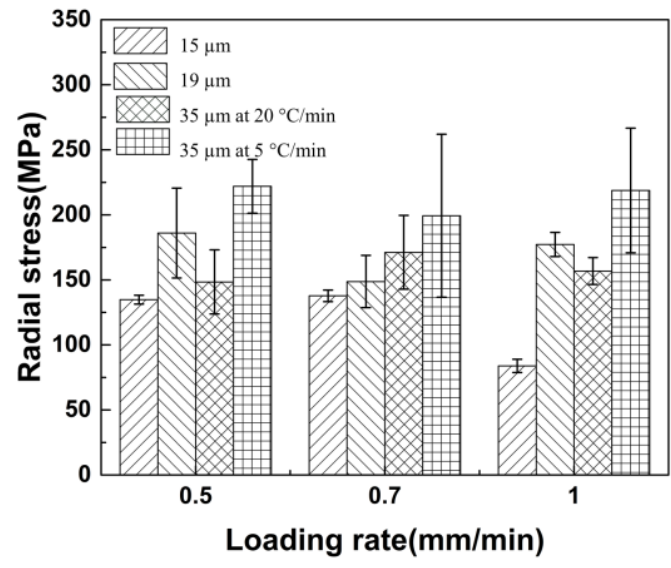

(a)

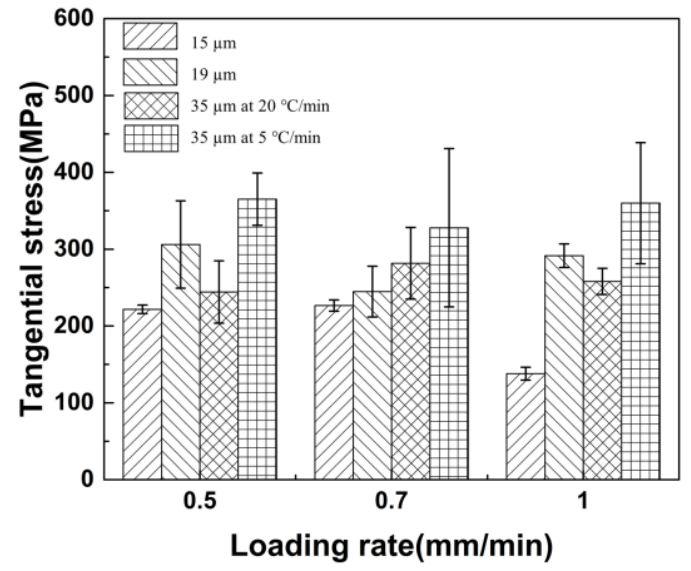

(b)

Fig. 8 (a) Radial and (b) tangential stress under the testing speed of $0.5,0.7$, and $1 \mathrm{~mm} / \mathrm{min}$. Default sintering rate for $15 \mu \mathrm{m}, 19 \mu \mathrm{m}$ and $35 \mu \mathrm{m}$ powder was $20^{\circ} \mathrm{C} / \mathrm{min} ; \mathrm{n}=3 ; 95 \%$ confidence intervals shown. 


\subsection{Fracture structure characterisation}

The dimpled fracture surfaces of the disk samples, indicating good sample sintering and ductility, are shown in Figure 9.

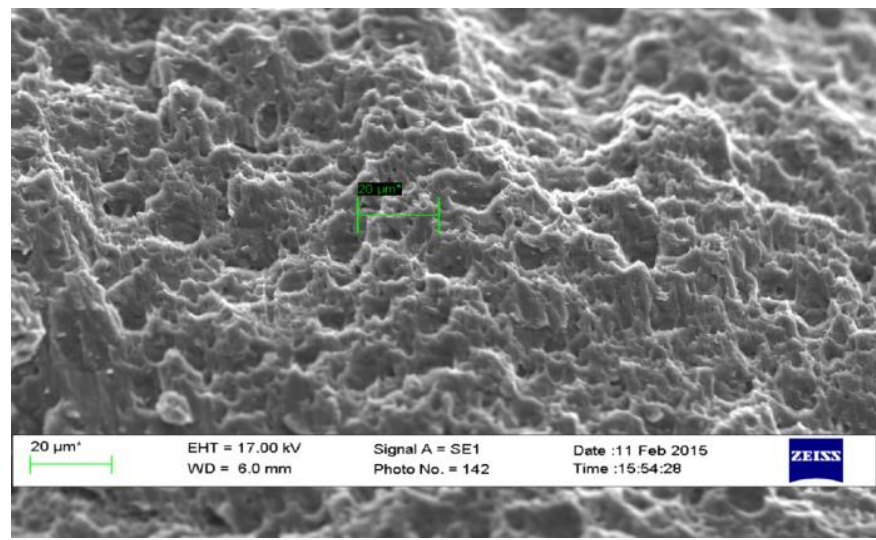

(a)

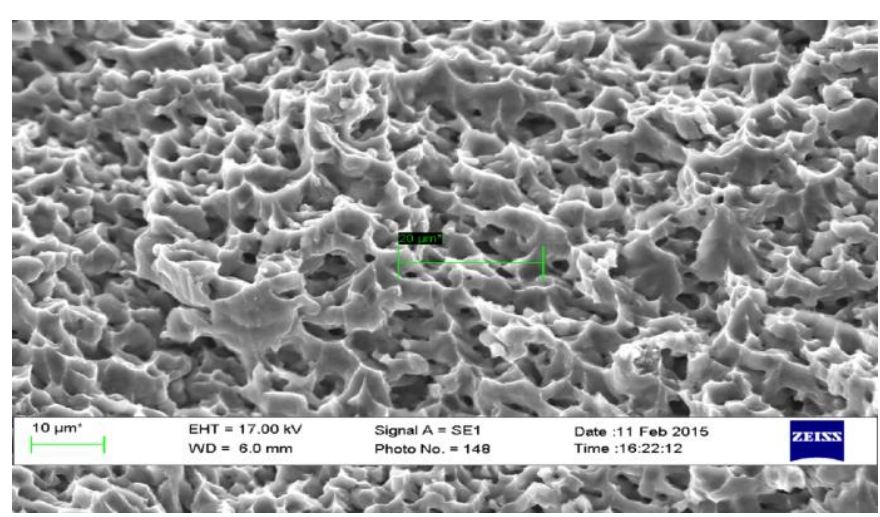

(b)

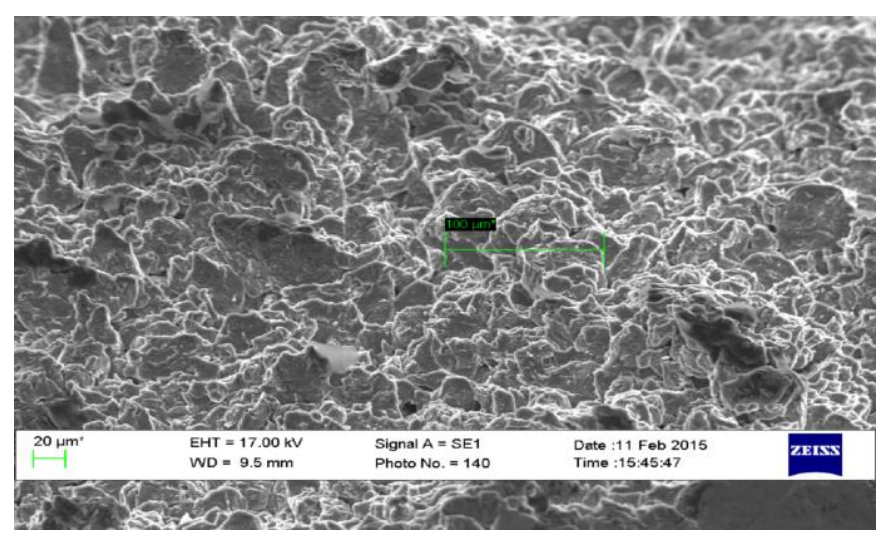

(c)

207 Figure 9: SEM photos of fracture morphology on cross sections of disk samples prepared with (a) $15 \mu \mathrm{m}$, 208 (b) $19 \mu \mathrm{m}$, and (c) $35 \mu \mathrm{m}$ powder, indicating the disk samples were uniformly sintered. 


\section{Results and discussion}

In this work, the $\mathrm{P} / \mathrm{M}$ route was used to produce pure aluminium disk samples from powders of mean particle size $15 \mu \mathrm{m}, 19 \mu \mathrm{m}$ and $35 \mu \mathrm{m}$. For green samples made from these powders, the compaction quality was influenced by compaction pressure, holding time, lubrication method, and powder quantity. The green sample quality, as measured by porosity, starts to deteriorate under insufficient pressure or by compaction with an uneven powder surface. These conditions result in final samples which are relatively fragile and brittle. The cold compaction and sintering process developed in this work produced relatively defect free disks by using a high compaction pressure (332 MPa) and a holding time of six minutes. The density obtained for the $35 \mu \mathrm{m}$ powder at the pressure of $332 \mathrm{MPa}$ was measured as $85.2 \%$. Stress values were very reproducible up to the cracking point, giving a strong baseline for comparison within this and future work, both for unmodified aluminium and aluminium composite systems [32-34]. The peak tangential stress values observed ranged from $137 \mathrm{MPa}$ to 365 $\mathrm{MPa}$. It was observed that the significant higher radial and tangential stress were achieved for the $35 \mu \mathrm{m}$ mean powder particle size samples produced with the lower heating rate of $5^{\circ} \mathrm{C} / \mathrm{min}$.

Robust sintering was achieved from the three aluminium particle sizes, as was observed from the analysis of the SEM images obtained for each surface. The SEM images of the lower particle size fracture sample surfaces, Fig. 9(a) and 9(b) showed more porous surfaces than was observed from the samples produced from the larger particle size, see Fig 9(c). The indentation load which lead to these fracture surfaces was applied centrally in the disk test specimens. There is a clear dimpled structure in the fractographs shown in Fig. 9 (a) and (b). These fracture structures are typical of those seem in the literature [35] and represent ductile material fracture where the pores are nucleated from dislocation build up at grain boundaries, followed by pore joining, and eventually to the point where the stress level is sufficient to break the remaining connected material. The samples produced with the larger $35 \mu \mathrm{m}$ average size particle showed higher levels of ductility and load bearing capability. The associated greater extent of fracture surface shearing and lower amount of dimpling is evident in this fracture surfaces, see Figure 9 (c).

The mechanical strength of the samples was found to be dependent on the sintering heating rate. The highest radial and tangential strengths were found for the largest particle size and the lower heating rate of $5^{\circ} \mathrm{C} / \mathrm{min}$. It is conjectured that the lower heating rate allowed time for atomic diffusion. Indentation testing results from the samples with the $35 \mu \mathrm{m}$ particles sintered using a heating rate of $5^{\circ} \mathrm{C} / \mathrm{min}$ exhibited the highest ductility and load bearing capability (400 MPa at $5 \mathrm{~mm}$ ) across the three loading rates tested. The error bars are however higher for the $35 \mu \mathrm{m}$ particle samples produced with a sintering rate of $5^{\circ} \mathrm{C} / \mathrm{min}$. The increased error bars for the slow heating rate are presumed to be due to the enhanced period for gas adsorption and entrainment within the aluminium. Even small concentrations of gases such as oxygen adsorption could lead to significant increase in sample porosity and hence reduction in sample mechanical properties.

The DTA results highlighted some variations in the melting temperature of the powders which may be associated to varying levels of sample purity and oxidation on the particles due to their varying surface area to volume 
ratios and the variance in the heat transfer through the crystal lattices of the samples by virtue of their differing

particle sizes, melt pool uniformity and oxidation levels. The presence of oxygen and/or nitrogen in the environment during DTA analysis as well as the smaller grain sizes of the powders could also influence the melting temperature. Further work on detailed TGA and XPS analysis of these particle phase changes and their surfaces chemistries respectively would allow for a more fundamental understanding and confirmation of the underlying causes of these results.

\section{Conclusion}

In this work, pure aluminium compacts have been produced with a number of particle sizes and tested at a number of indentation speeds to establish their physical mechanical behaviour. To achieve stable green and sintered disk samples, the P/M technique of green compaction and sintering was optimized. Well-formed green samples and sintered specimen of variable particle sizes were then obtained. The indentation results indicate that under the identical testing speed, that the $35 \mu \mathrm{m}$ powder at $5{ }^{\circ} \mathrm{C} / \mathrm{min}$ sintering rate provided the highest radial and tangential strength, closely followed by the $35 \mu \mathrm{m}$ powder at $20^{\circ} \mathrm{C} / \mathrm{min}$ sintering rate. This is considered to be due to the make-up of the $35 \mu \mathrm{m}$ powder which had a mixed morphology and a wide particle size range. This significantly improved the material strength by reducing porosity in the consolidated and sintered structures. The lower surface area to volume ratio of the larger particles provides relatively more aluminium volume and a lower barrier to inter-particle atom diffusion and binding. Another important finding from this work is the increase in sintered compact strength which was achieved by using a lower heating rate. In this work, this resulted in a tangential stress value of $365 \mathrm{MPa}$ which was significantly higher than for the faster sintering heating rate, 244 $\mathrm{MPa}$. The reason for this is believed to be that the lower heating rate allowed increased time and hence extent of atomic diffusion between particles. The $15 \mu \mathrm{m}$ powder sample provided the lowest strengths among all samples. This is likely due to the increased alumina to aluminium volume of the smaller particles making it more difficult for aluminium atomic diffusion between particles. The P/M process on high purity aluminium powders examined in this paper presents processing conditions for obtaining pure aluminium samples of definable strength. The presence of a stable oxide layer is a major restriction in the exploitation of the conventional sintering process for smaller aluminium powder particles. However, methods of overcoming these problems can be implemented such as modification of surface oxide distribution, removal of stable surface oxides, and exploitation of the surface oxide chemistry. In future work, the combination of the controlled process as proposed in this paper with oxide reduction methods will be examined. For example, oxide concentration may be reduced using a fluxing agent such as acetamide, zinc chloride, or sodium fluoride [36]. The addition of magnesium is also known to disrupt the passivating oxide layer via the formation of a spinel phase [37]. These will be examined for the niche applications of relatively pure metallic applications previously noted such as for electrical and electronic applications. 


\section{References}

[1] Dursun T, and Soutis C (2014) "Recent developments in advanced aircraft aluminium alloys," Materials and Design, vol. 56. pp. 862-871.

[2] Brandt R, and Neuer G (2007) "Electrical resistivity and thermal conductivity of pure aluminum and aluminum alloys up to and above the melting temperature," Int. J. Thermophys., vol. 28, no. 5, pp. 1429-1446

[3] De Matteis G, Brando G, Mazzolani F M (2012) "Pure aluminium: An innovative material for structural applications in seismic engineering," Constr. Build. Mater., vol. 26, no. 1, pp. 677686.

[4] Hirsch J (2004) “Automotive Trends in Aluminium-The European Perspective," Mater. Forum, vol. 28, pp. 15-23.

[5] Soares B, and Dantas S (2017) "Corrosion of aluminum for beverage packaging in acidic media containing chlorides and copper ions," J. Food Process Engineering, DOI: 10.1111/jfpe. 12571.

[6] Fasoyiro S, Gourama H, and Cutter C (2017) "Stability and safety of maize-legume-fortified flours stored in various packaging materials," Eur. Food Res., pp. 1-8.

[7] Zulkifli F, Ali N, Yusof M S M, Khairul W M, Rahamathullah R, Isa M I N, Wan Nik W B (2017) "The effect of concentration of Lawsonia inermis as a corrosion inhibitor for aluminum alloy in seawater," Adv. Phys. Chem.,https://doi.org/10.1155/2017/8521623

[8] Dudin M, Voykova N, Frolova E, Artemieva J (2017) "Modern trends and challenges of development of global aluminum industry," Metalurgija, vol 56.

[9] Mandal N, (2017) "Material of Construction," Sh. Constr. Weld., pp91-109 2017 Ship Construction and Welding pp 91-109.

[10] Yu H, Li R, Qian M, Ma H, Hou J "The Development of High Strength-High Conductive Aluminum Conductors," Proc.2016 International Conference on Electrical Engineering and Automation (EEA2016). DOI: 10.1142/9789813220362_0039

[11] Taguchi K,Akasofu Y, Yoshimoto J (2017) "Development of High Strength Aluminum Wires for Low-Voltage Automotive Wiring Harnesses," SAE Int. J. Engines, doi:10.4271/2017-011644 .

[12] Cui X, Wu Y, Zhang G, Liu Y, Liu X, (2017) "Study on the improvement of electrical conductivity and mechanical properties of low alloying electrical aluminum alloys," Compos. Part B Eng., vol. 110, pp. 381-387.

[13] Cousseau R, Patin N, Forgez C, Monmasson E, Idkhajine L (2017) "Improved electrical model of aluminum electrolytic capacitor with anomalous diffusion for health monitoring," Math. Comput. Simul., vol. 131, pp. 268-282.

[14] Du X, Lin B, Li B, Feng T, Mao S, Xu Y (2017) "Surface Modification of Al Foils for Aluminum Electrolytic Capacitor,” Adv. Funct. Mater., vol. 27, pp 1606042.

[15] Wette J, Sutter F, Fernández-García A,Ziegler S, Dasbach R (2016) "Comparison of 
Degradation on Aluminum Reflectors for Solar Collectors due to Outdoor Exposure and Accelerated Aging," Energies, vol. 9, no. 11, p. 916.

[16] Mishra S K, Kumar V, Tiwari S K, Mishra T, Angula G, Adhikari S (2016) "Development and degradation behavior of protective multilayer coatings for aluminum reflectors for solar thermal applications," Thin Solid Films, vol. 619, pp. 202-207.

[17] Liu J, O'Connor WJ, Ahearne E, Byrne G (2013) Electromechanical modelling for piezoelectric flextensional actuators. Smart Materials and Structures 23 (2) pp.1-13

[18] Hsiang S H, Lin Y W, Lai J W "Optimization of hot extrusion process for AZ61 magnesium alloy carriers,” Int. J. Mater. Form., vol. 5, no. 3, pp. 259-268, Sep. 2012.

[19] Sornin D, Karch A, Nunes D, "Finite element method simulation of the hot extrusion of a powder metallurgy stainless steel grade," Int. J. Mater. Form., vol. 8, no. 1, pp. 145-155, Mar. 2015.

[20] Güley V, Ben Khalifa N, Tekkaya A E "Direct recycling of 1050 aluminum alloy scrap material mixed with 6060 aluminum alloy chips by hot extrusion," Int. J. Mater. Form., vol. 3, no. SUPPL. 1, pp. 853-856, Apr. 2010.

[21] Widerøe F, Welo T, Vestøl H "A new testing machine to determine the behaviour of aluminium granulate under combined pressure and shear," Int. J. Mater. Form., vol. 3, no. S1, pp. 861-864, Apr. 2010.

[22] Brosius A, Hermes M, Ben Khalifa N, Trompeter M, Tekkaya A E "Innovation by forming technology: motivation for research," Int. J. Mater. Form., vol. 2, no. S1, pp. 29-38, Aug. 2009.

[23] Totten GE, MacKenzie DS (2003) Handbook of Aluminum: Vol. 1: Physical Metallurgy and Processes, Taylor \& Francis.

[24] Verlinden B, Froyen L (1994) Aluminium Powder Metallurgy. European Aluminium Association.

[25] Gökçe A, Fındık F (2008) Mechanical and physical properties of sintered aluminum powders. Journal of achievements in materials and manufacturing engineering 30 (2) pp.157-164

[26] Djuricic M, Dragojlovic M, Novakovic R (1986) Cold Sintering of Aluminum and Its Alloys, Science of Sintering 18: pp. 87-89

[27] Sabirov I, Perez-Prado M T, Murashkin M, Molina-Aldareguia J M, Bobruk E V, Yunusova N F, Valiev R Z (2010) "Application of Equal channel Angular Pressing with Parallel Channels for Grain Refinement in Aluminium Alloys and its Effect on Deformation Behaviour" Int J Mater Form. vol. 3 Suppl 1:pp411 - 414

[28] ElRakayby H, KiTae Kim K, "Effect of glass container encapsulation on deformation and densification behavior of metal powders during hot isostatic pressing" Int J Mater Form, DOI $10.1007 / \mathrm{s} 12289-017-1361-8$

[29] Okuma S (1979) The Sintering Mechanism of Aluminium and the Anodization of Aluminium Sintered Bodies. Active and Passive Electronic Components 6 (1): pp. 23-29

[30] Hearn EJ (1997) Mechanics of Materials, Volume 2 - An Introduction to the Mechanics of Elastic and Plastic Deformation of Solids and Structural Materials. vol 2, 3rd edn. Elsevier,

[31] Timoshenko S, Woinowsky-Krieger S (1959) Theory of plates and shells, Engineering Societies Monographs. McGraw-Hill, New York 
[32] Liu, J., Fernandez, B., Rodriguez, P., Naher, S., Brabazon, D (2016) Powder processing methodology for production of graphene oxide reinforced aluminium matrix composites, Advances in Materials and Processing Technologies, 2, 4, pp. 437-450

[33] Liu, J., Khan, U., Coleman, J., Fernandez, B., Rodriguez, P., Naher, P., Brabazon, D (2016) Graphene oxide and graphene nanosheet reinforced aluminium matrix composites: Powder synthesis and prepared composite characteristics, Materials \& Design, 94, pp. 87-94

[34] Dasari, B., Nouri, JM., Brabazon, D., Naher, S (2017) Graphene and derivatives - Synthesis techniques, properties and their energy applications, Energy, 140, pp. 766-778

[35] ASM Handbook. Volume 12: Fractography, 1987, ISBN: 978-0-87170-018-6.

[36] Kowalski, L., Korevaar, B. M., Duszczyk, J (1992) Some new aspects of the theory of oxidation and degassing of aluminium-based alloy powders, J. Mater. Sci. 27, pp2770-2780. doi:10.1007/BF00540704

[37] Lumley, R.N., Sercombe, T. B., Schaffer, G. M (1999) Surface oxide and the role of magnesium during the sintering of aluminum, Metall. Mater. Trans. A. 30, pp457-463. doi:10.1007/s11661-999-0335-y 


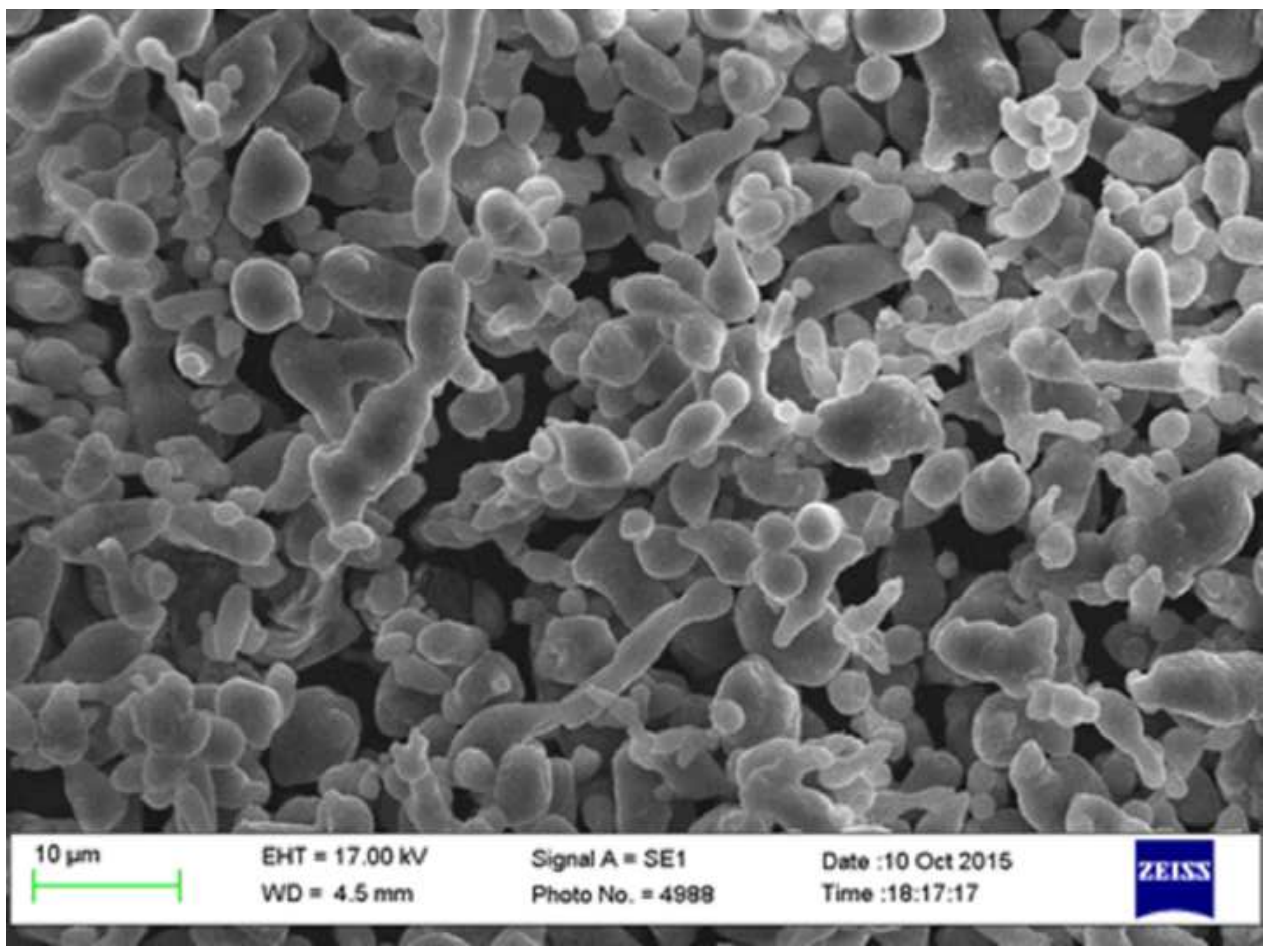


Click here to download Figure Figure 1(b).png $\underline{\underline{*}}$

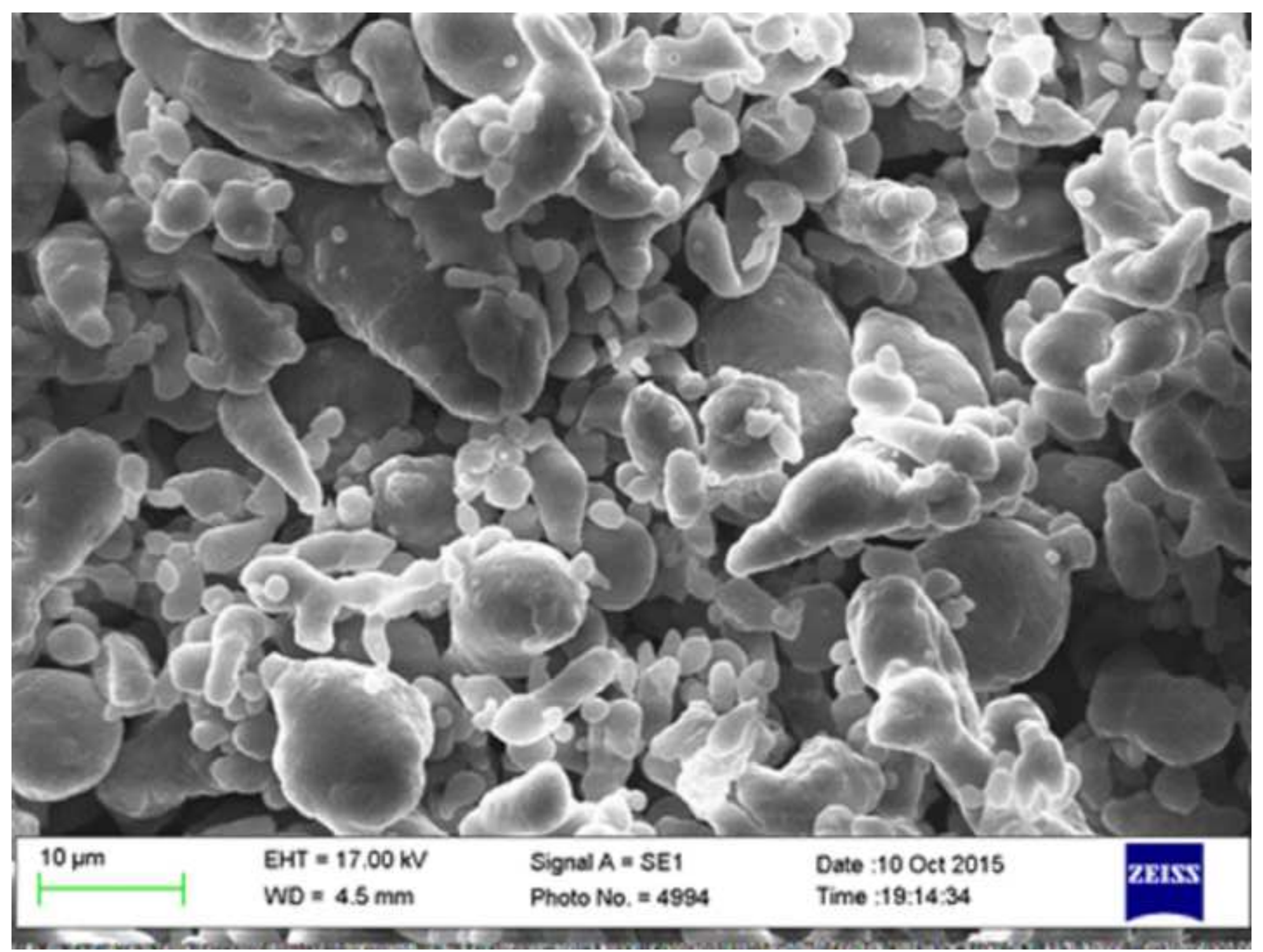




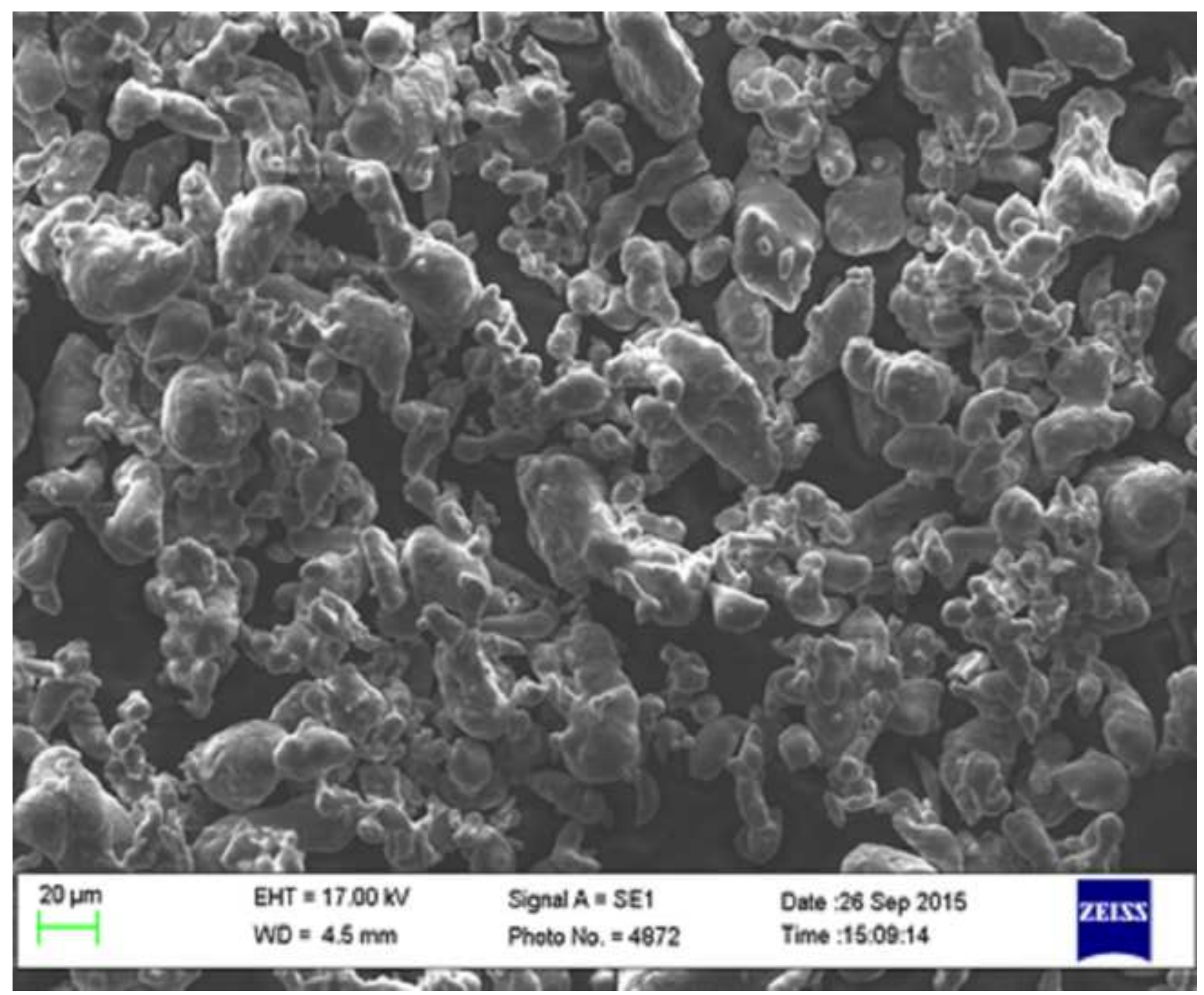




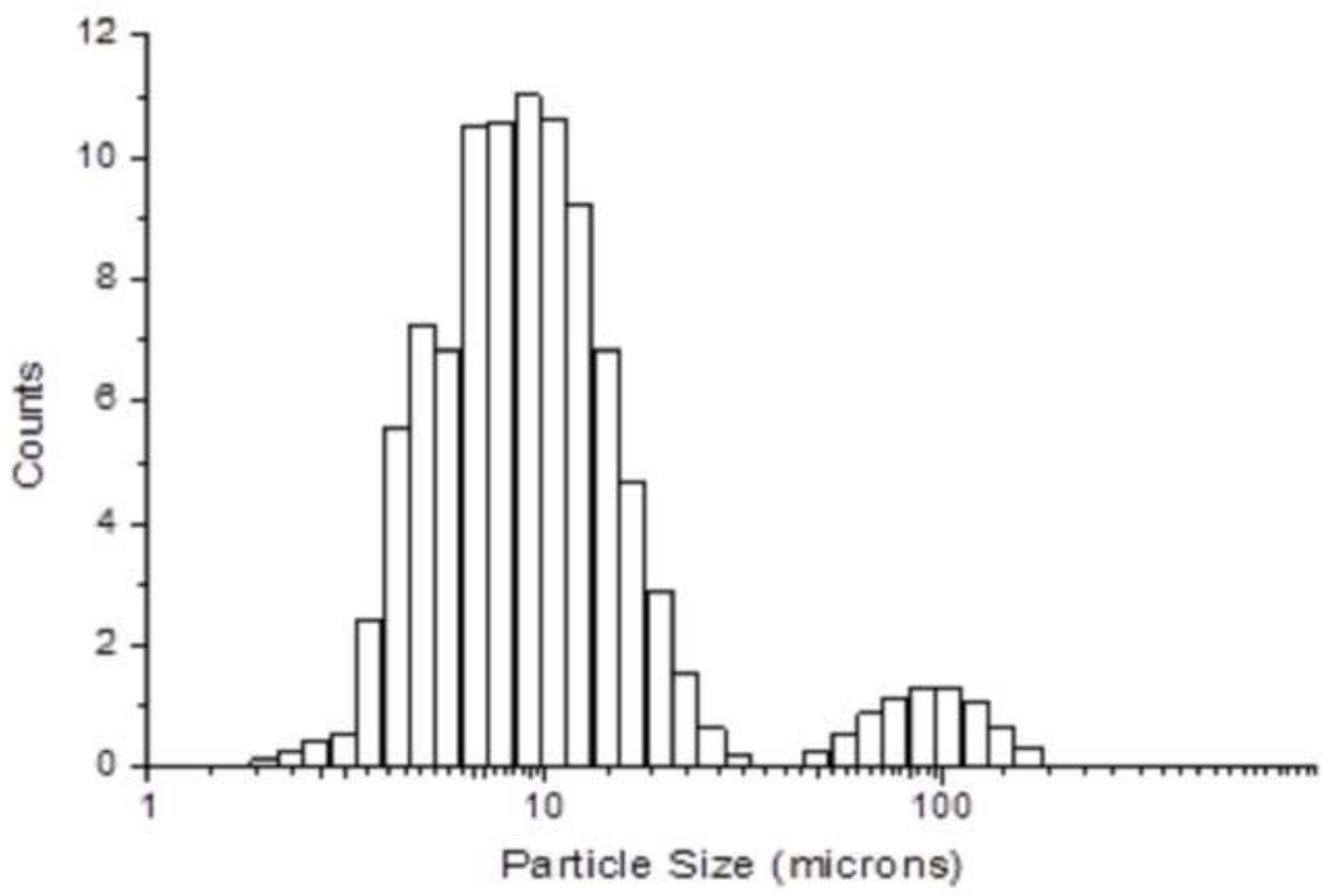




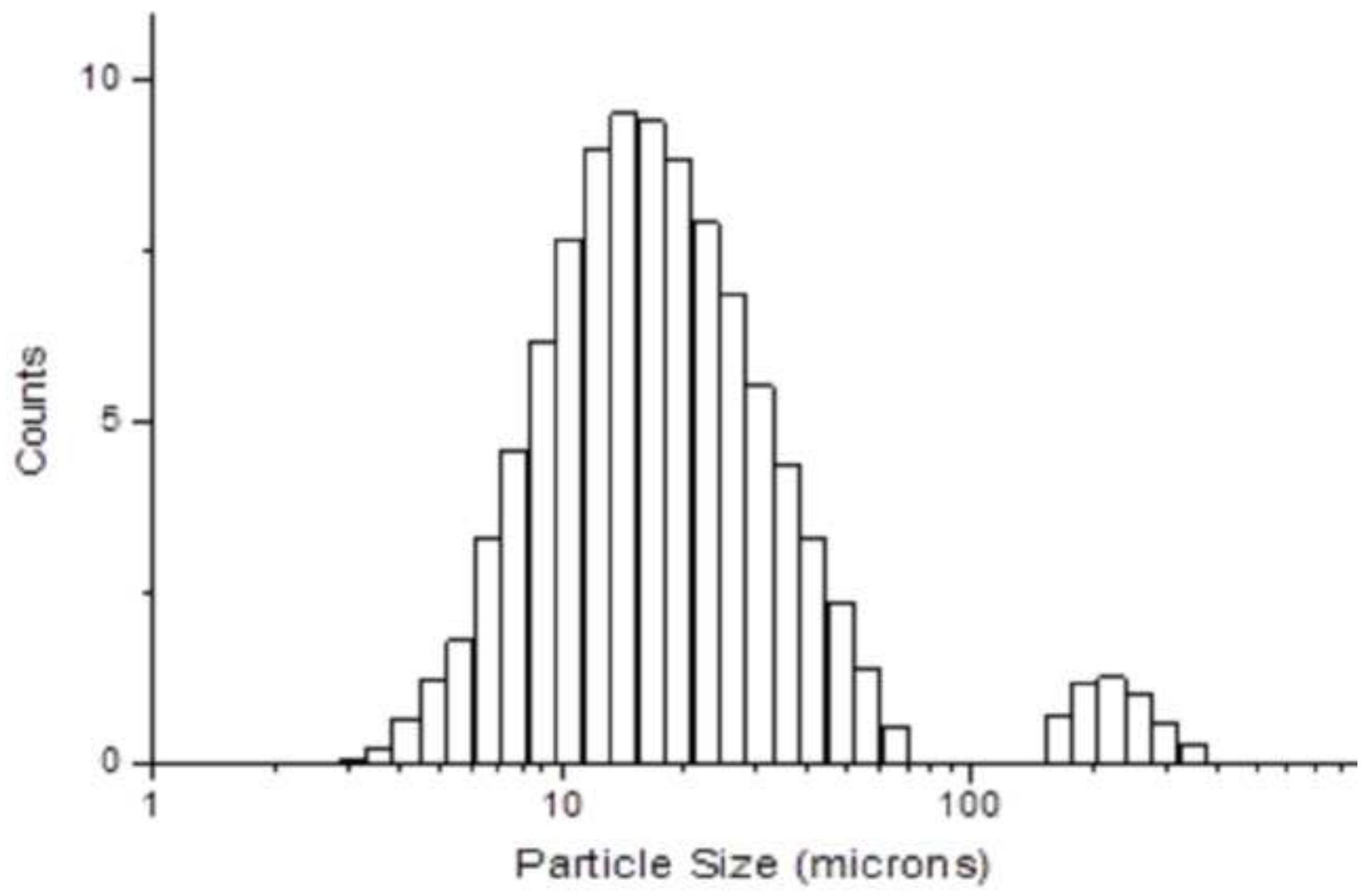




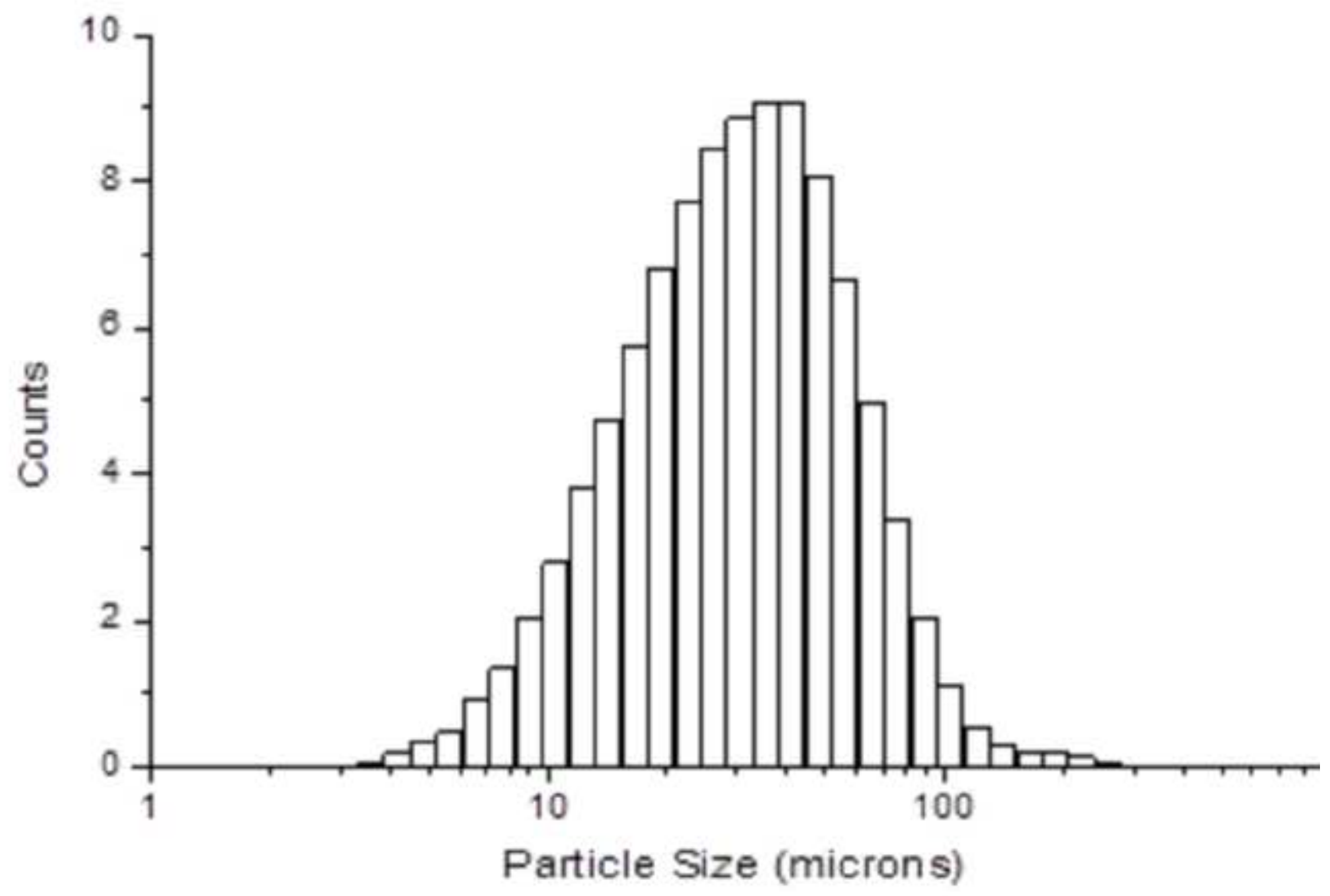


Click here to download Figure Figure 2.png $\underline{\underline{ \pm}}$

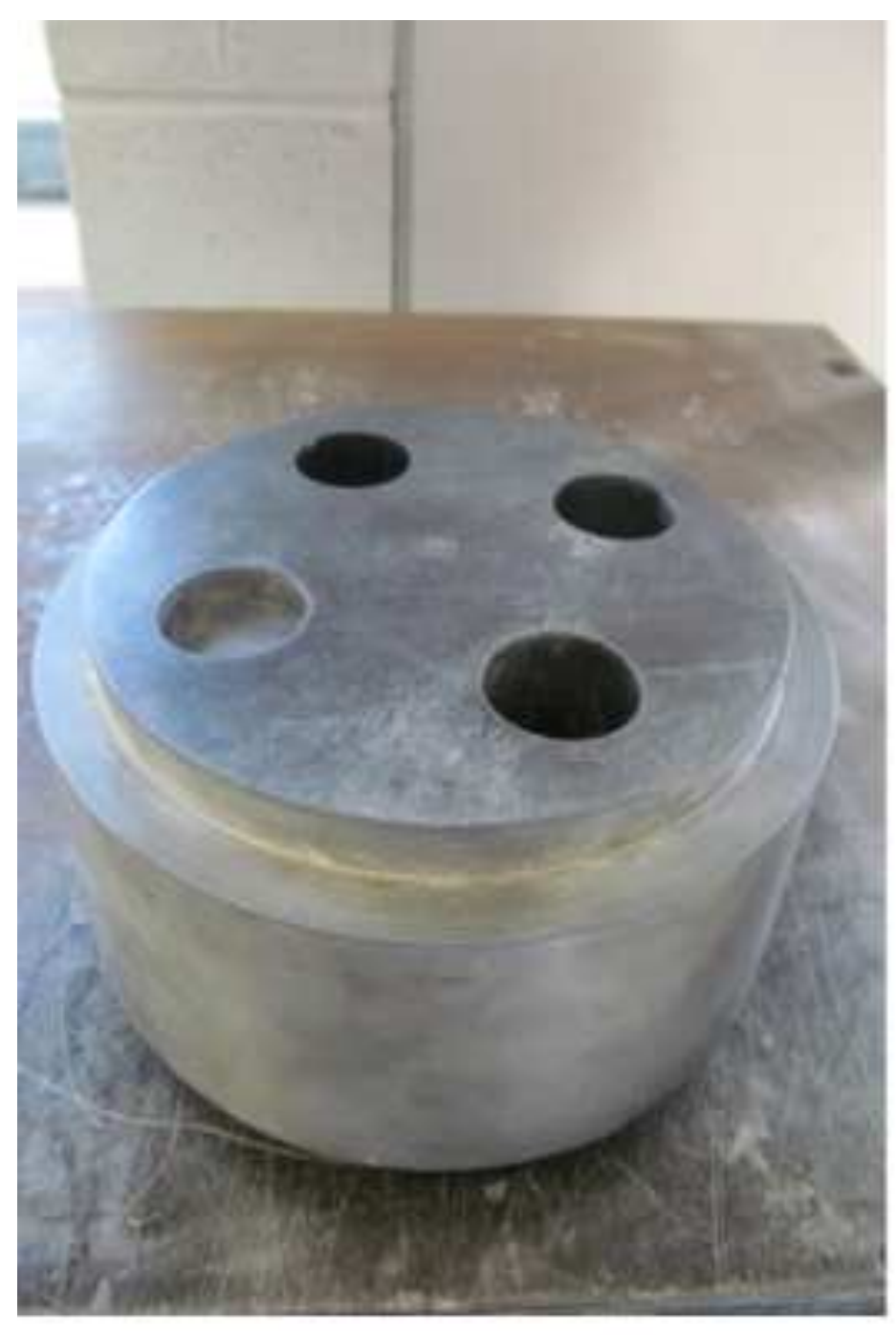

(a)

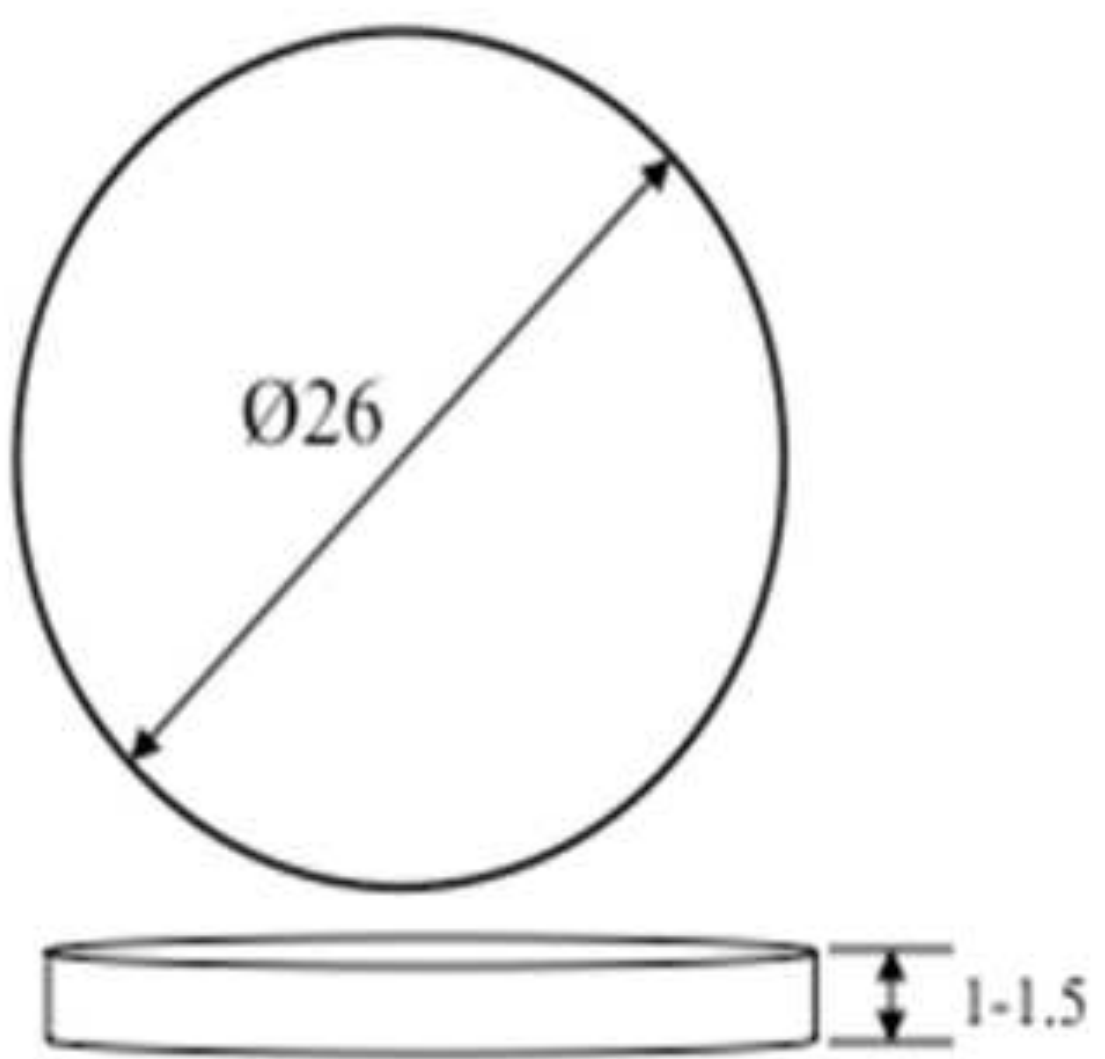

(b) 


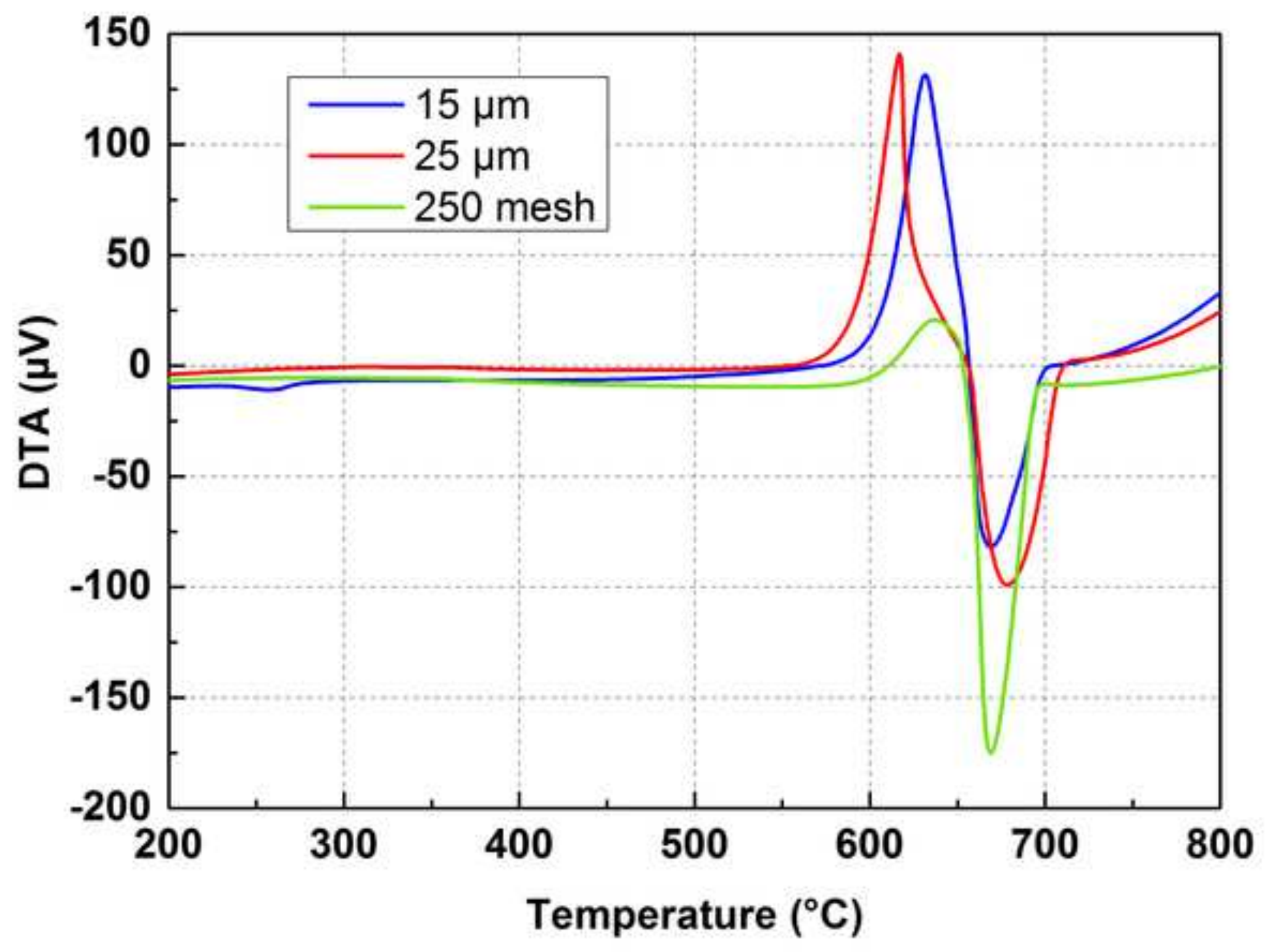


Click here to download Figure Figure 4 (a).png $\underline{\underline{\Perp}}$

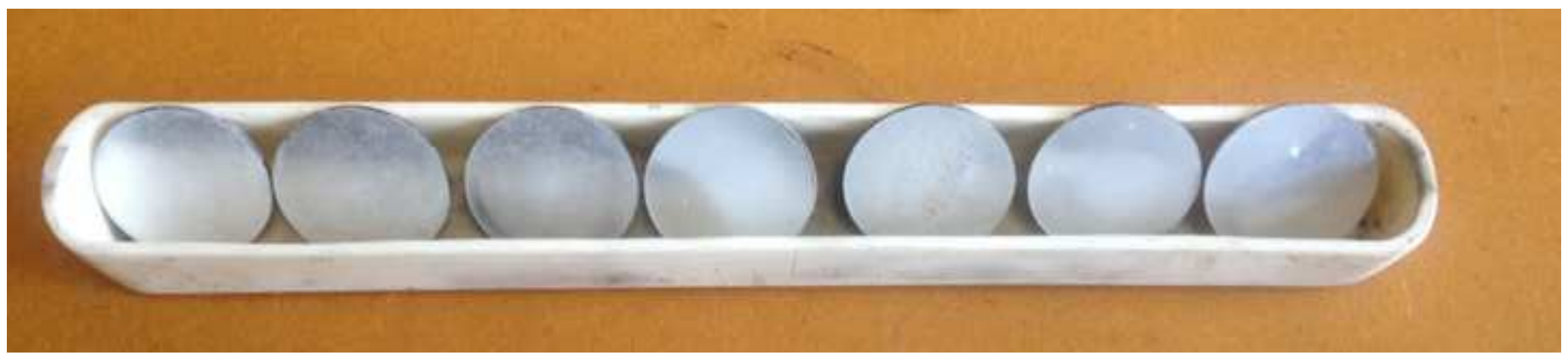


Click here to download Figure Figure 4 (b).png $\underline{\underline{ \pm}}$

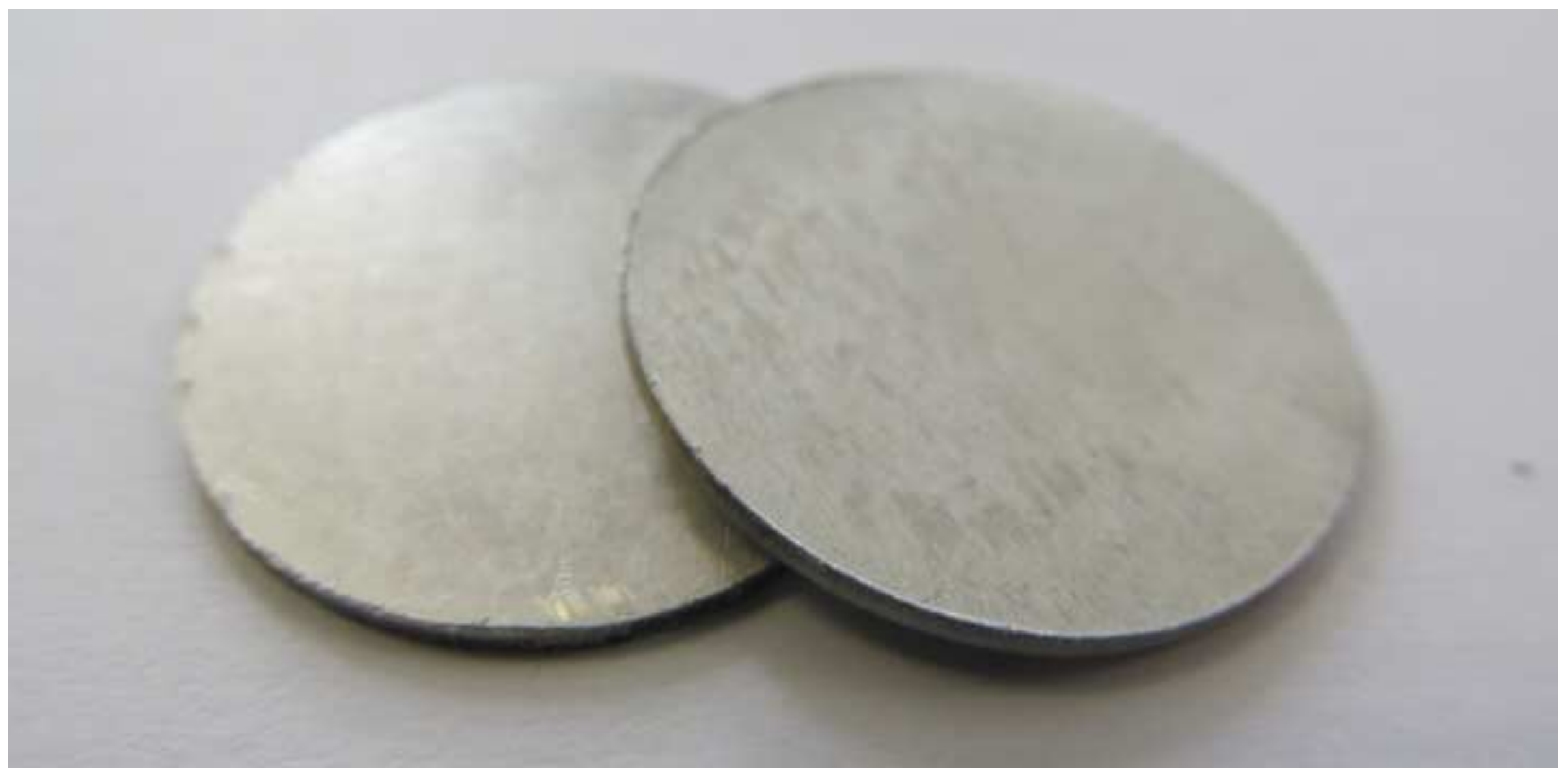




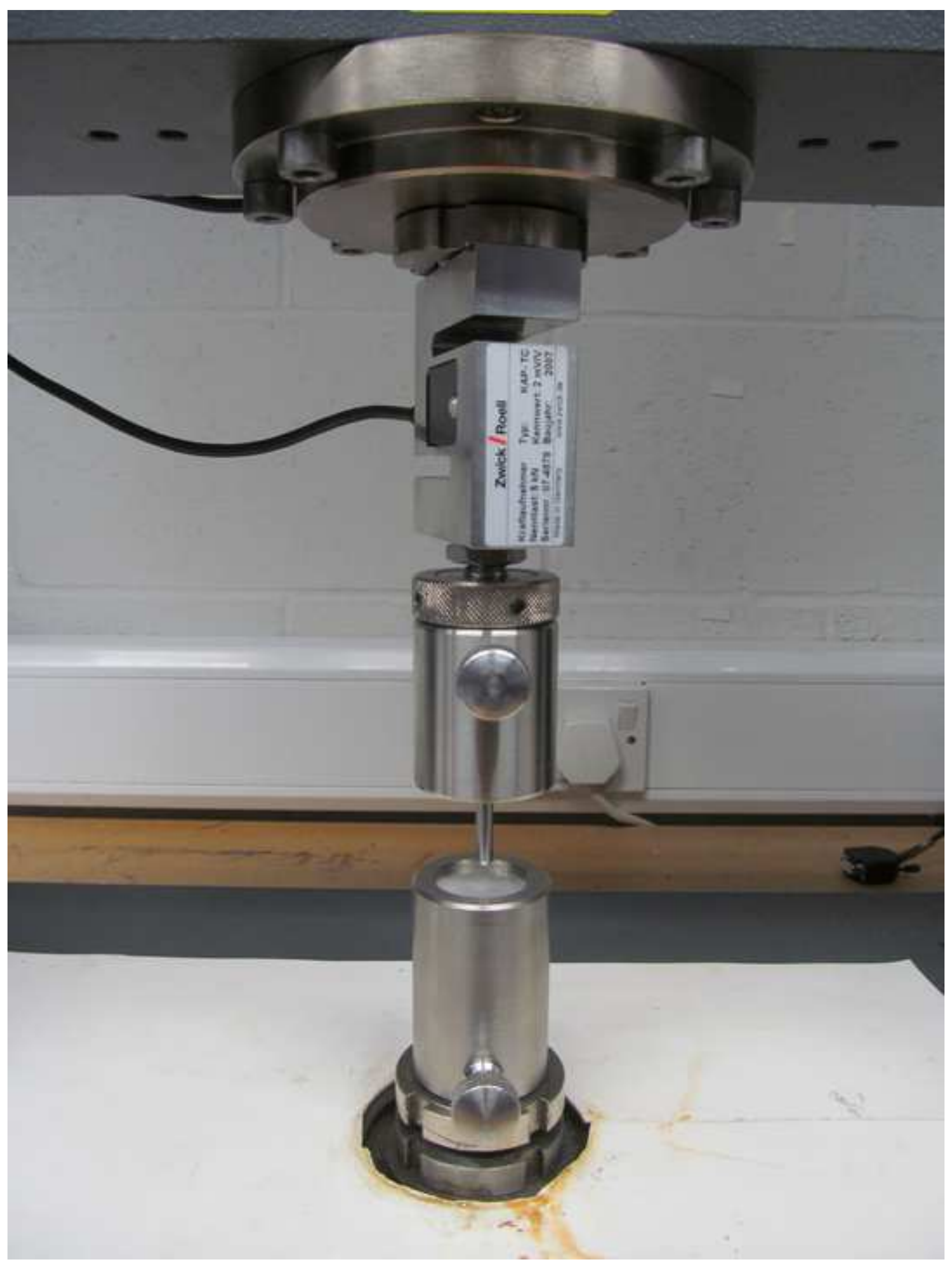




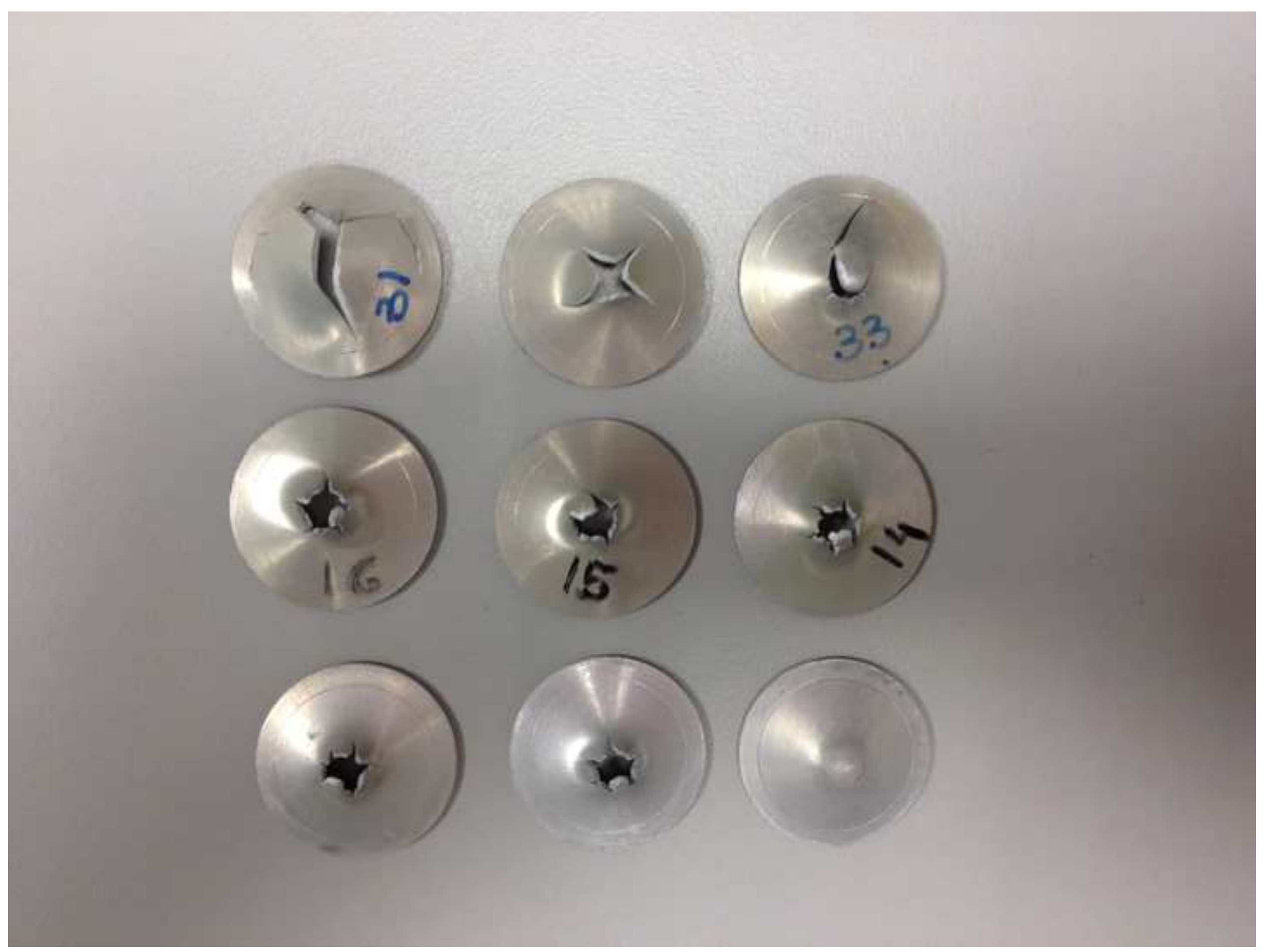




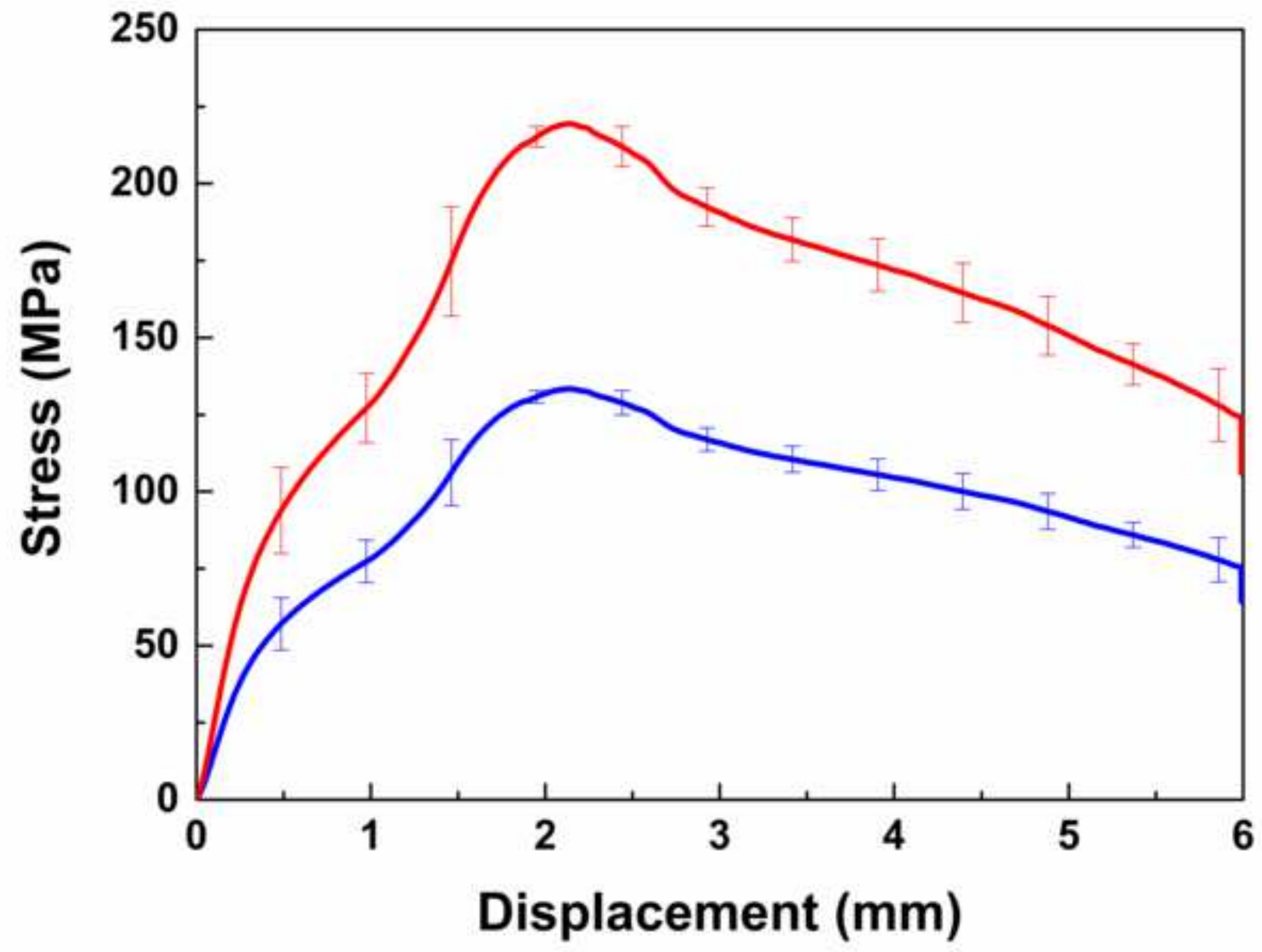




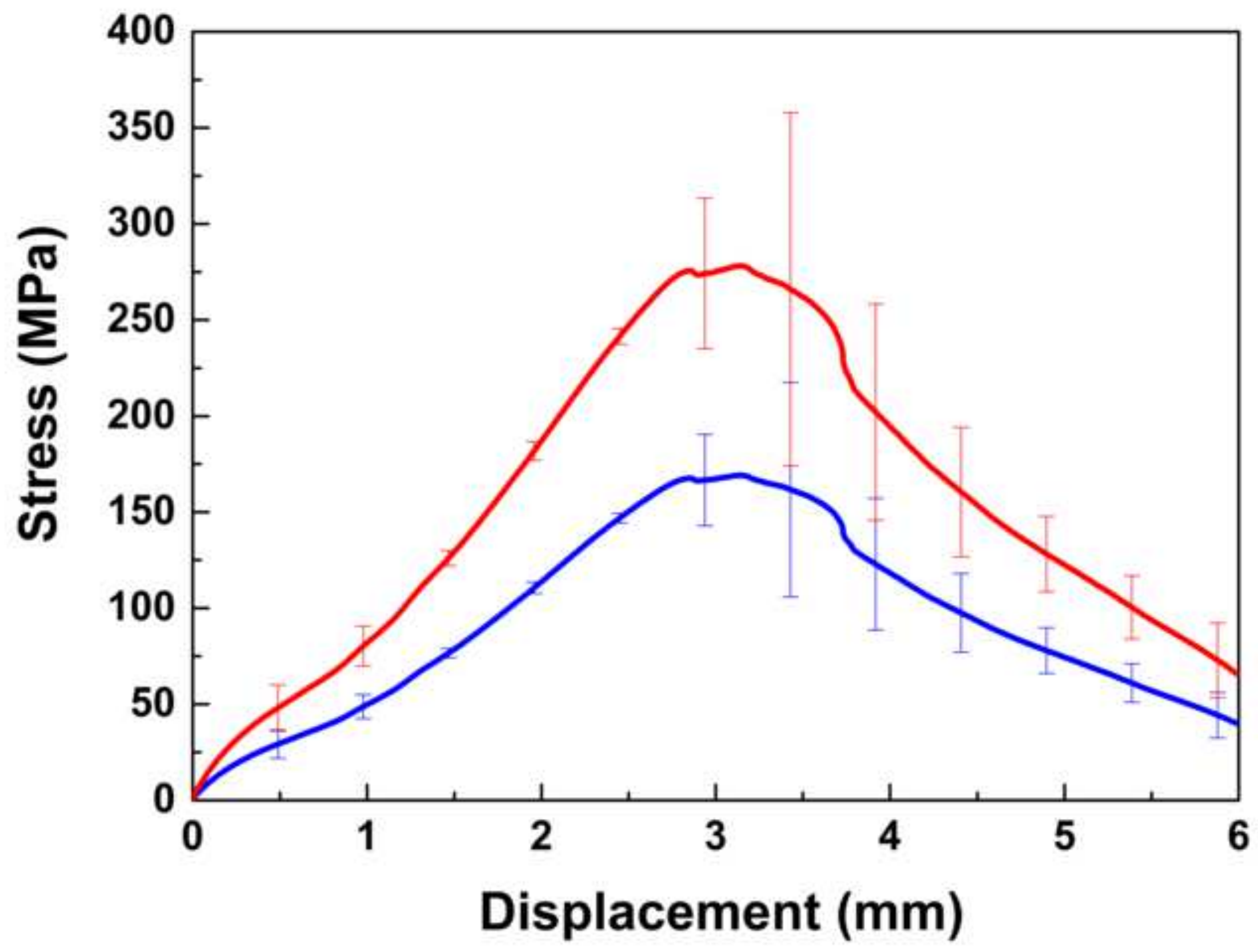




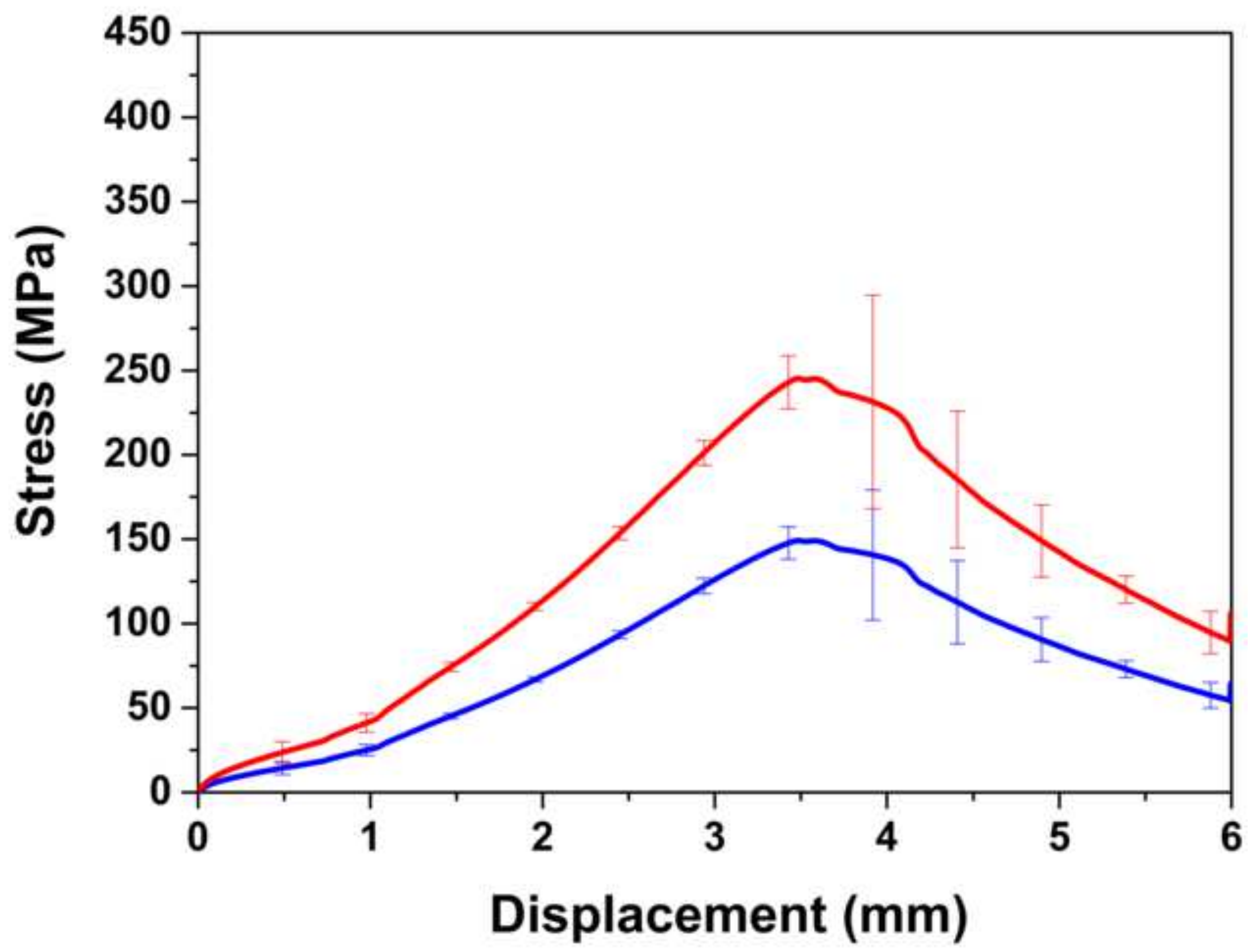




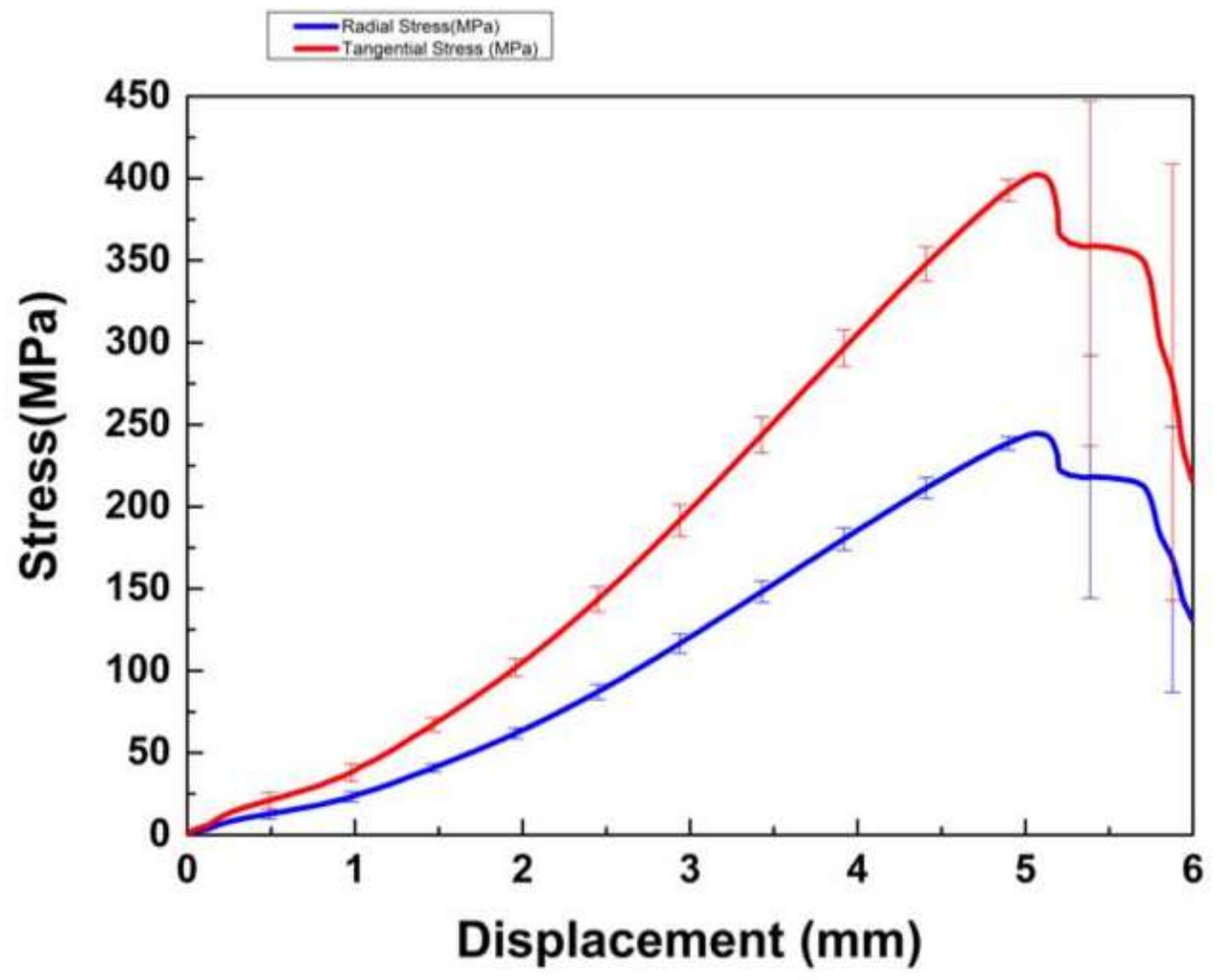




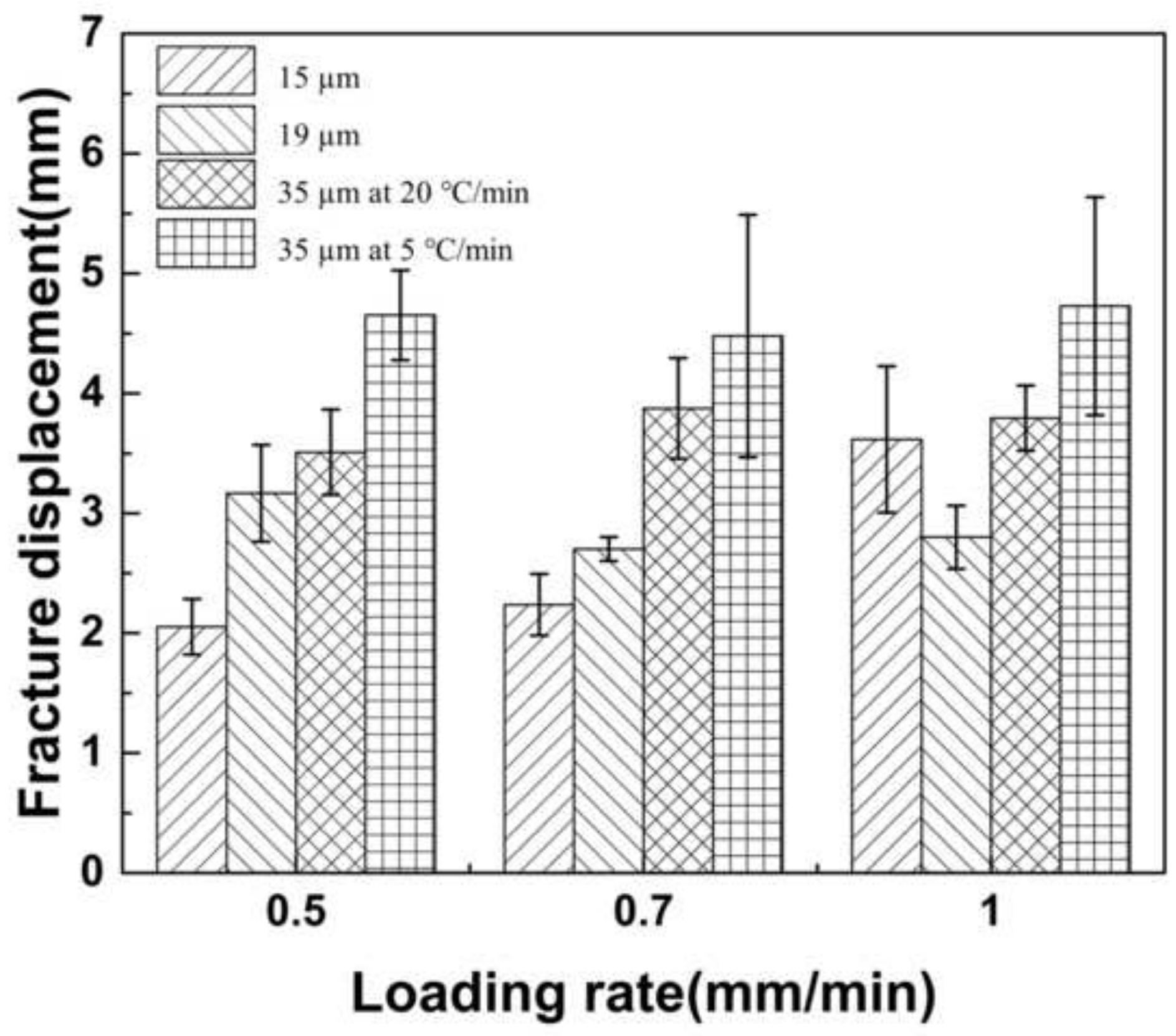




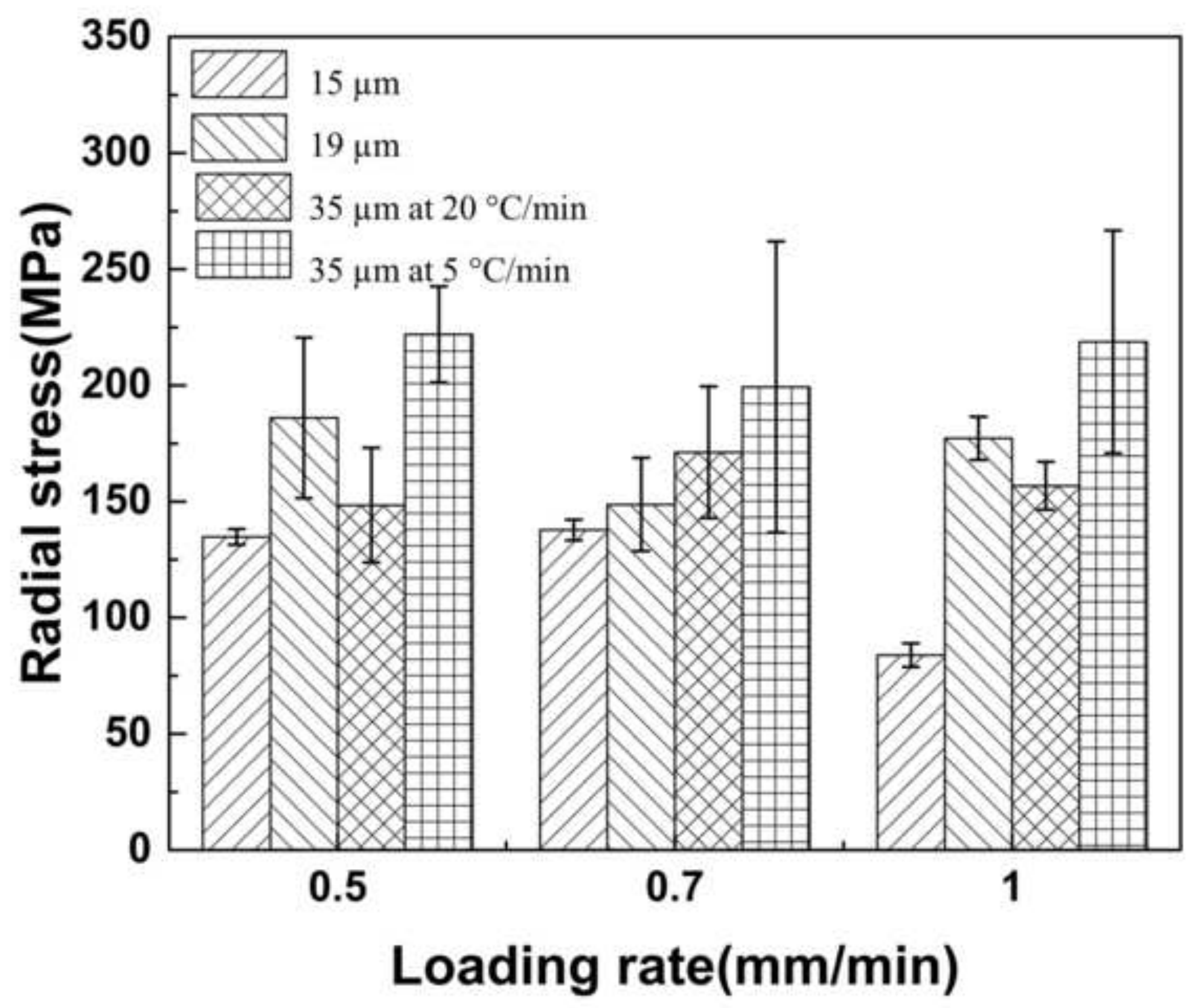




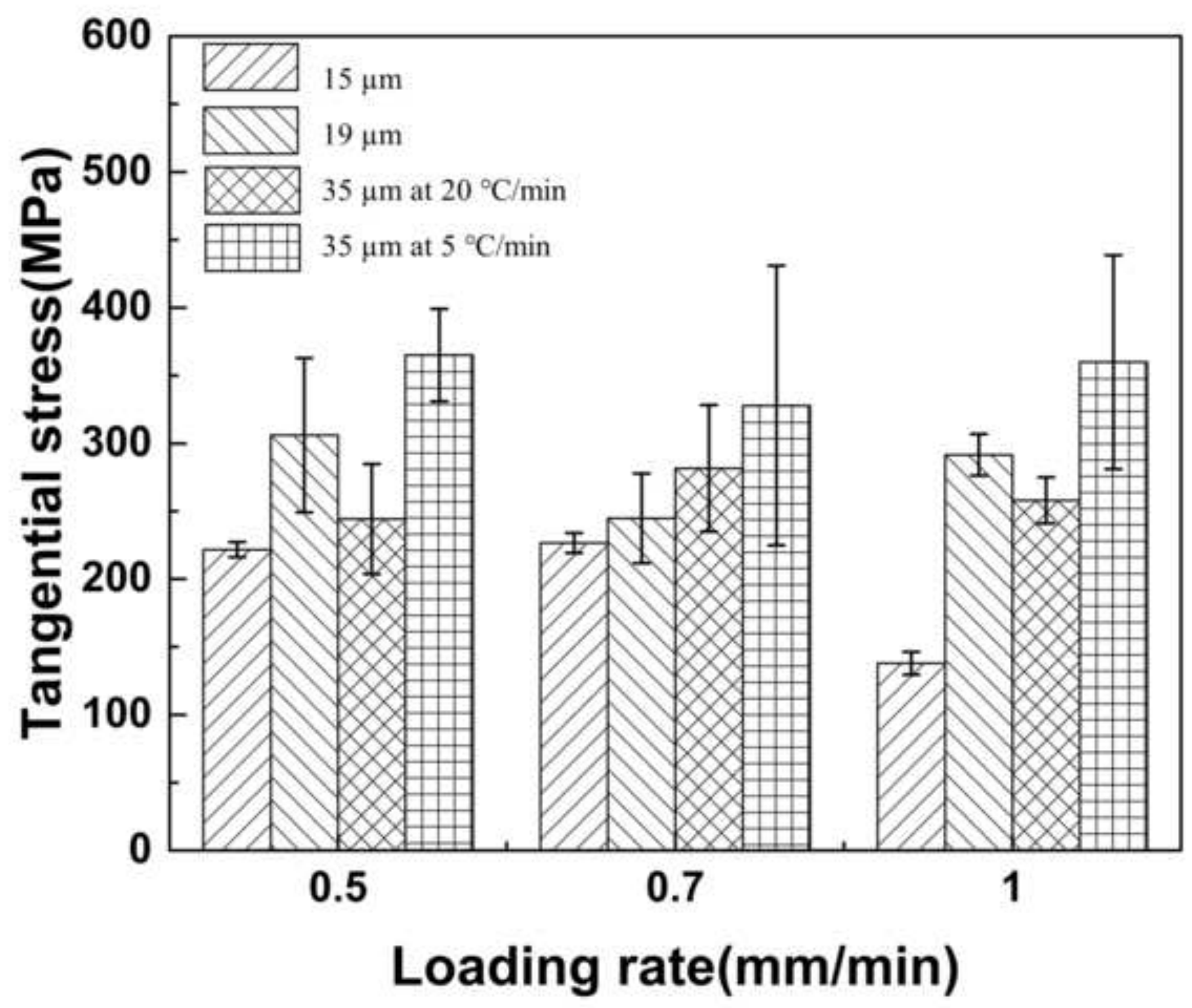




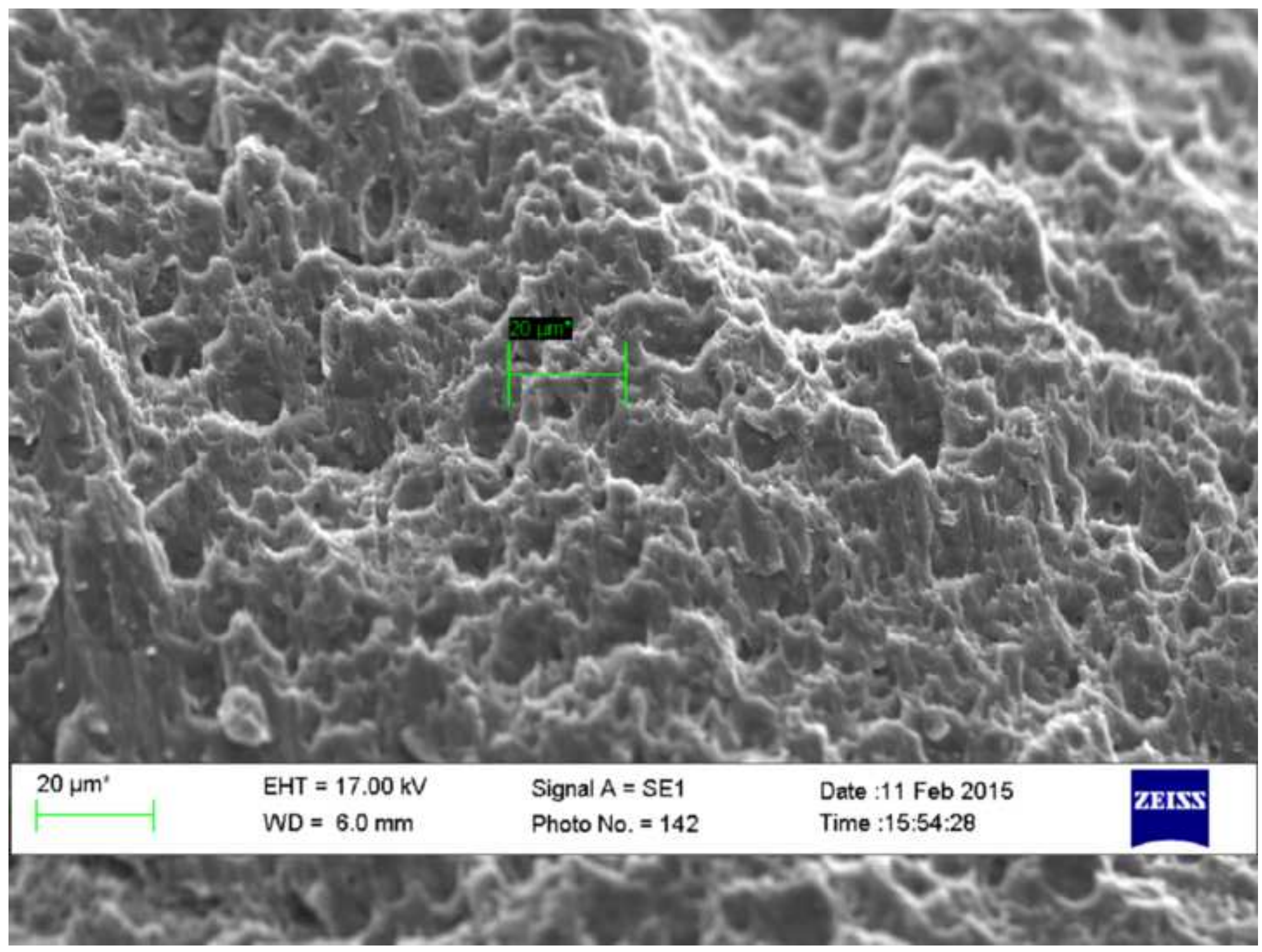




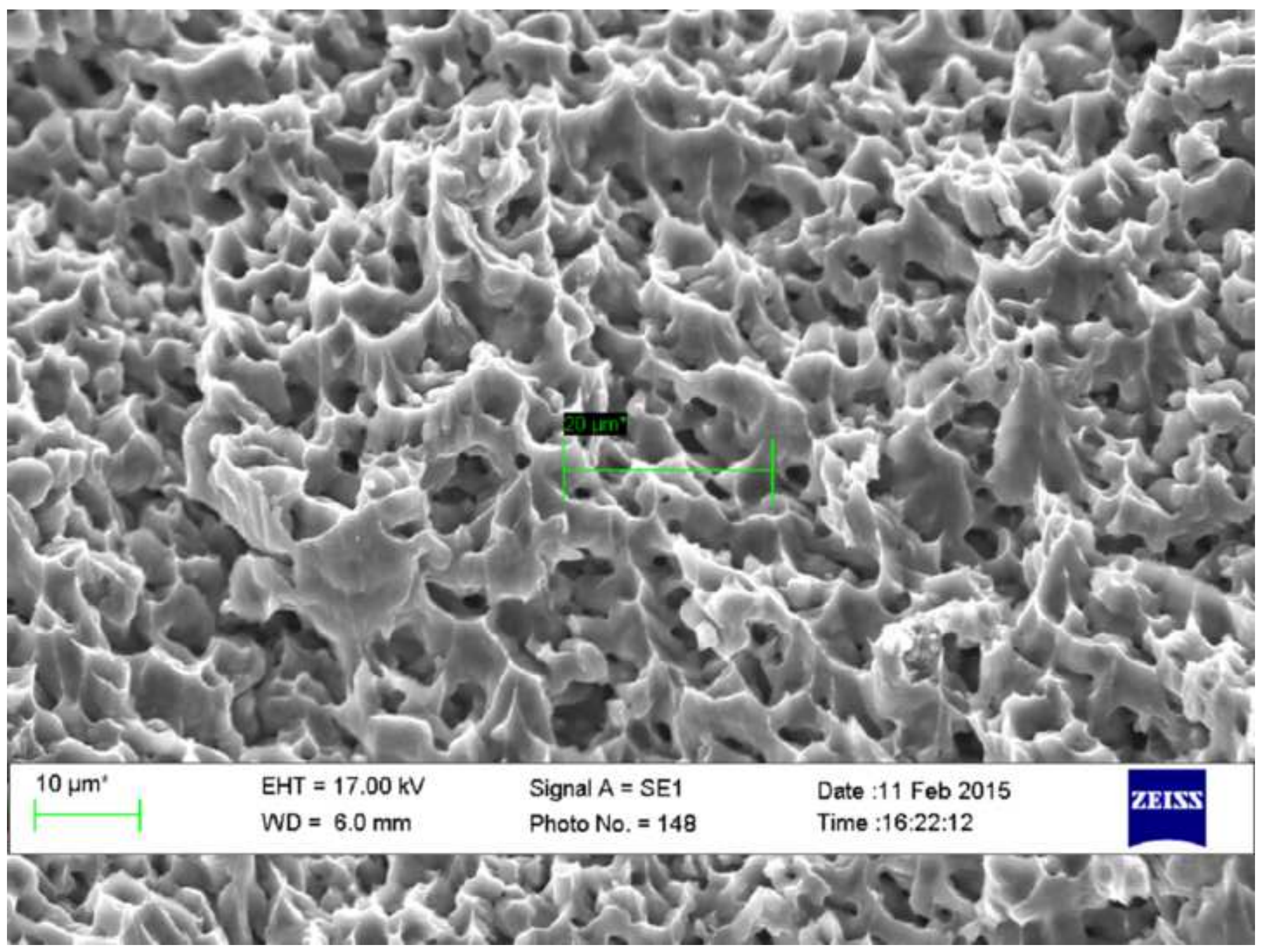




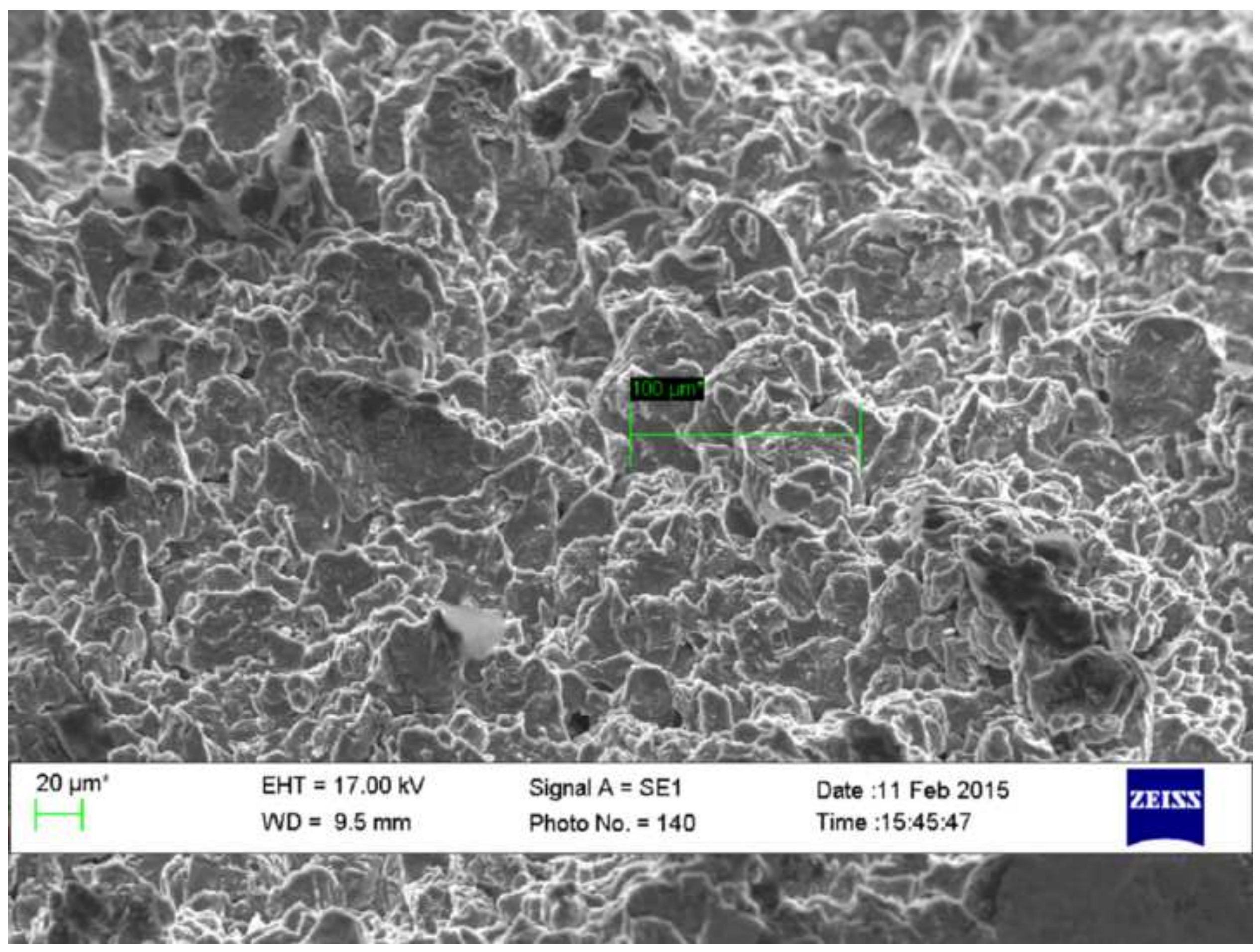

